Report Title:

Report Type:

Reporting Period Start Date:

Reporting Period End Date:

Principal Author:

Report Issued:

DOE Award Number:

Submitting Organization:

\section{Efficient Adjustable Reflectivity Smart Window}

Final

October 1, 2003

October 30, 2005

D. Morgan Tench

(805) 373-4509

mtench@rwsc.com

December 2005

DE-FC26-03NT41951

Rockwell Scientific Company LLC

1049 Camino Dos Rios

Thousand Oaks, CA 91360

This report was prepared as an account of work sponsored by an agency of the United States Government. Neither the United States Government nor any agency thereof, nor any of their employees, makes any warranty, express or implied, or assumes any legal liability or responsibility for the accuracy, completeness, or usefulness of any information, apparatus, product, or process disclosed, or represents that its use would not infringe privately owned rights. Reference herein to any specific commercial product, process, or service by trade name, trademark, manufacturer, or otherwise does not necessarily constitute or imply its endorsement, recommendation, or favoring by the United States Government or any agency thereof. The views and opinions of authors expressed herein do not necessarily state or reflect those of the United States Government or any agency thereof. 


\subsection{ABSTRACT}

This project addressed the key technical issues for development of an efficient smart window based on reversible electrochemical transfer of silver between a mirror electrode and a localized counter electrode. Effort to provide uniform switching over large areas focused on use of a resistive transparent electrode innerlayer to increase the interelectrode resistance. An effective edge seal was developed in collaboration with adhesive suppliers and an electrochromic device manufacturer. Work to provide a manufacturable counter electrode focused on fabricating a dot matrix electrode without photolithography by electrodeposition of Pt nuclei on inherent active sites on a transparent oxide conductor. An alternative counter electrode based on a conducting polymer and an ionic liquid electrolyte was also investigated.

Work in all of these areas was successful. Sputtered large-bandgap oxide innerlayers sandwiched between conductive indium tin oxide (ITO) layers were shown to provide sufficient cross-layer resistance $\left(>300 \mathrm{ohm} / \mathrm{cm}^{2}\right)$ without significantly affecting the electrochemical properties of the ITO overlayer. Two edge seal epoxies, one procured from an epoxy manufacturer and one provided by an electrochromic device manufacturer in finished seals, were shown to be effective barriers against oxygen intrusion up to $80^{\circ} \mathrm{C}$. The optimum density of nuclei for the dot matrix counter electrode was attained without use of photolithography by electrodeposition from a commercial alkaline platinum plating bath. Silver loss issues for cells with dot matrix electrodes were successfully addressed by purifying the electrolyte and adjusting the cell cycling parameters. More than $30 \mathrm{~K}$ cycles were demonstrated for a REM cell $(30-\mathrm{cm}$ square) with a dot matrix counter electrode. Larger cells (30-cm square) were successfully fabricated but could not be cycled since the nucleation layers (provided by an outside supplier) were defective so that mirror deposits could not be produced. 


\section{TABLE OF CONTENTS}

1.0 Abstract 2

2.0 Executive Summary 4

3.0 REM Smart Window Description 6

4.0 Project Results and Discussion 7

$\begin{array}{lll}4.1 & \text { Uniform Mirror Switching } & 7\end{array}$

4.1.1 High-Resistivity Gelled Electrolyte Development 7

4.1.2 Programmed Voltage Switching 9

$\begin{array}{ll}\text { 4.1.3 Optimum Cell Design } & 10\end{array}$

4.1.3.1 Resistive Electrode Innerlayer 10

4.1.3.2 Gelled Electrolyte Considerations 13

4.1.3.3 Electrical Modeling 14

$\begin{array}{lll}4.2 & \text { Edge Seal Development } & 16\end{array}$

4.3 Counter Electrode Development 21

$\begin{array}{ll}\text { 4.3.1 Dot Matrix Electrode Concept } & 21\end{array}$

4.3.2 Dot Matrix Electrode Fabrication 22

4.3.2.1 Substrate Material Selection 23

4.3.2.2 Platinum Plating Bath Selection 24

4.3.2.3 Dot Density Consistency 25

4.3.2.4 ITO Pretreatment Effects 28

4.3.3 Dot Matrix Electrode Testing 29

4.3.3.1 Rapid Silver Loss $\quad 30$

4.3.3.2 Slow Silver Loss 32

4.3.3.3 Extraneous Silver Deposition 37

4.3.3.4 Silver Loss Prevention 39

4.3.4 Conducting Polymer Counter Electrode 41

4.4 Demonstration Device Fabrication 42

4.4.1 Automated Dot Counting 43

4.4.2 Plating of Large-Area Dot Matrix Electrode 43 


\subsection{EXECUTIVE SUMMARY}

Smart windows permit the amount of light and heat transmitted into transportation vehicles and buildings to be controlled so as to reduce glare, enhance occupant comfort, and reduce energy consumption and costs for air conditioning and heating. Currently available electrochromic devices are not effective for saving energy since they absorb the light, which is converted into heat that is largely transferred into the interior space by conduction, convection and infrared radiation.

A new reversible electrochemical mirror (REM) technology developed by Rockwell Scientific offers the possibility of a smart window that is more than $80 \%$ efficient at preventing solar heating (twice the efficiency of electrochromic devices). For the REM smart window device, silver metal is reversibly electrodeposited (from a thin layer of gelled electrolyte) as a full or partial mirror on a transparent platinized indium tin oxide (ITO) electrode to provide variable reflectivity, and is deposited on a metal grid counter electrode to increase the amount of light transmitted. Visible light transmission continuously variable from about $80 \%$ to complete light blocking has been demonstrated for devices with grid electrodes. White light reflectance variable from less than $5 \%$ to about $80 \%$ has been demonstrated and a maximum reflectance of about $85 \%$ should be attainable. Intermediate REM mirror states provide good visibility to the exterior and have a pleasing bluish-gray appearance. Switching is accomplished with low voltage $(0.5 \mathrm{~V})$, and no voltage is needed to maintain a given switched state. Cycle life of more than 200,000 cycles has been demonstrated for variable reflectivity devices with continuous counter electrodes.

This project addressed the key remaining technical issues for commercialization of REM smart window devices by providing: (1) uniform switching over large areas; (2) an effective edge seal; and (3) a manufacturable counter electrode to replace the expensive metal grid electrode fabricated via photolithography.

Effort to provide uniform switching over large areas focused on use of a resistive transparent electrode innerlayer to increase the interelectrode resistance. Thin sputtered innerlayers of the wide-bandgap metallic oxides $\mathrm{TiO}_{2}, \mathrm{~A}_{2} \mathrm{O}_{3}$ and $\mathrm{SnO}_{2}$ sandwiched between a highly conductive ITO underlayer (20 ohm/sq.) and a less conductive ITO overlayer (100 $\mathrm{ohm} / \mathrm{sq}$.) were shown to provide the resistance needed for uniform switching of large-area REM devices ( $>300 \mathrm{ohms} / \mathrm{cm}^{2}$ for $3000 \AA$ innerlayers). In addition, such innerlayers were shown to have a negligible effect on the properties of the sputtered ITO overlayer since the density of platinum nuclei plated on the overlayer for dot matrix electrodes was the same as that for the bare ITO underlayer. These results demonstrate the feasibility of the innerlayer approach. Modeling work showed that a graded innerlayer (thicker near the bussbars) could provide the constant potential switching needed for high mirror uniformity over large areas. Alternative approaches that were considered include gelling the electrolyte with a polymer to increase the electrolyte resistance, and using a dual-pulse drive voltage to periodically redistribute the mirror deposit.

The seal issue for REM devices was successfully addressed. A proprietary seal provided by an electrochromic device manufacturer was shown to be compatible with the 
GBL electrolyte used in REM cells and to provide an effective barrier against oxygen intrusion. Silver loss for cells with this seal was negligible after 77 days at $80^{\circ} \mathrm{C}$ in air, which represents a severe accelerated aging test. Two epoxies identified in collaboration with adhesives suppliers also gave good results but were not as effective as the commercial seal at $80^{\circ} \mathrm{C}$ due to issues associated with hand assembly. In particular, failure tended to occur at the fill hole used to insert the electrolyte, which was sealed with epoxy cured at room temperature since equipment for applying focused light and heat was not available. These epoxy seals would apparently be acceptable for long-term use with the caveat that a better procedure is needed at RSC for plugging the fill hole.

Work to develop a manufacturable counter electrode focused on electrodepositing micron-sized islands of platinum at inherent active sites on a continuous layer of ITO transparent conductor. Reversible electrodeposition of silver on the platinum islands permits silver to be efficiently removed from the light path to provide high light transmission and fast switching but the island density is critical. The optimum density of platinum islands (1 - 3 million $/ \mathrm{cm}^{2}$ ) was consistently attained via use of a commercial alkaline plating bath. The island density is very insensitive to ITO sputtering variables and etching treatments, making the electrode fabrication process robust and amenable to large-scale use.

The key cycle life issue for cells with dot matrix electrodes was found to be silver loss resulting from reaction of the silver metal (used for mirror formation) with impurities from the electrolyte and epoxy seal. Silver loss is a particular issue for smart window devices since the amount of silver stored on the dot matrix must be limited to avoid excessive light blocking in the transmissive state. Acceptable silver loss rates were attained by distilling the GBL solvent and improving the seal cure procedure to minimize detrimental impurities, and limiting the applied voltage to avoid extraneous silver deposition on the exposed ITO surface. Cycle life of more than 30,000 cycles was demonstrated.

A large-area demonstration device (30-cm square) was fabricated but could not be characterized or cycle tested since mirror formation was not observed due to a defective platinum nucleation layer provided by an outside supplier. The nucleation layer problem was verified and shown to result from defective ITO by building smaller cells with the same ITO material platinized at RSC. A smaller demonstration device (10-cm square) was delivered to the DOE.

An alternative counter electrode based on a conducting polymer and an ionic liquid electrolyte was also investigated. In this case, silver loss is not an issue since the counter electrode reaction is oxidation/reduction of the conducting polymer rather than reversible silver electrodeposition, and extra silver can be stored along the perimeter of the cell (out of the light path). Polyaniline as the counter electrode is optically transparent when the REM mirror is erased and switches to green as the REM mirror is formed. Thus, the polyaniline counter electrode provides an additional electrochromic effect that masks reflection from the backside of the REM mirror. Demonstration cells built with polyaniline counter electrodes were successfully tested but could not be subjected to long-term cycling due to the remedial assembly procedure used. 


\subsection{REM Smart Window Description}

As illustrated in Fig. 1, current transmissive REM devices involve a simple electrochemical cell comprised of a thin layer of electrolyte, containing electrodepositable silver ions, sandwiched between two transparent electrodes on glass or plastic substrates. One electrode is a coating of ITO transparent conductor with a very thin $(15 \AA)$ overlayer of platinum metal, which improves nucleation so that a mirror electrodeposit is obtained. The second electrode is a fine grid or dot matrix of inert metal, e.g. Pt, on which silver can be deposited so as to have a minimal effect in blocking light transmission. To increase the device reflectivity, a voltage is applied such that a silver mirror is deposited on the platinized ITO mirror electrode while silver is dissolved from the grid electrode. To decrease window reflectivity, the cell polarity is reversed so that the silver mirror is dissolved (partially or fully) from the mirror electrode, and silver is plated onto the grid lines of the counter electrode. Such a REM system involves a net reversible transfer of the same metal from the mirror state at one electrode to a distributed localized state at the other electrode. Transmission and reflection of REM devices for visible white light can be varied continuously over a wide range. Very little power is required for switching REM devices, and it is not necessary to maintain an applied voltage to preserve a given switched state.

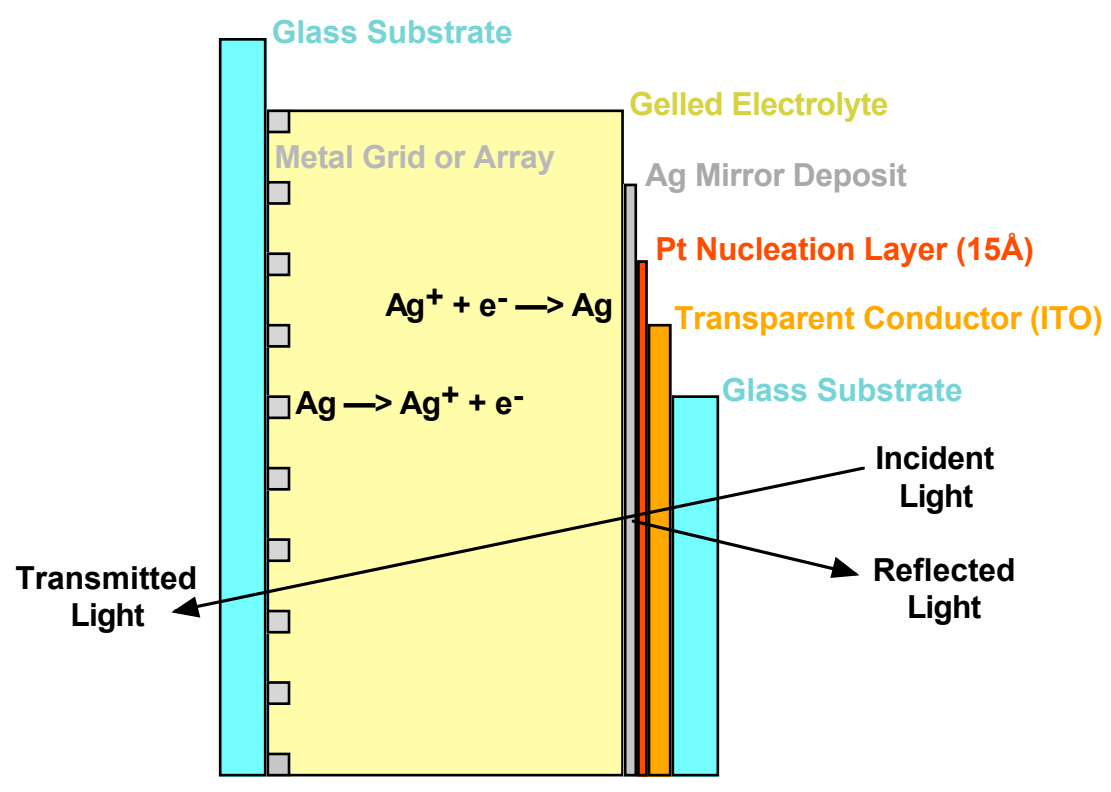

Fig. 1 Schematic of a REM smart window device. 


\subsection{Project Results and Discussion}

This project addressed the key remaining technical issues for commercialization of REM smart window devices by providing: (1) uniform switching over large areas; (2) an effective edge seal; and (3) a manufacturable counter electrode to replace the expensive metal grid electrode fabricated via photolithography. The project was divided into four technical tasks. The first three tasks were directed toward addressing the key technical issues, and the fourth task was directed toward providing smart window demonstration devices. Results for each task are described below.

\subsection{Uniform Mirror Switching}

Because of the appreciable sheet resistance for the ITO electrodes used in REM cells (typically $10 \mathrm{ohms} / \mathrm{square}$ ), switching current densities tend to be smaller toward the center of the cell (away from the buss bars) due to the voltage drops in the electrodes. This tends to cause "irising" during mirror formation and erasure. Most of the irising effect results from the voltage drop in the counter electrode since the sheet resistance of the mirror electrode is greatly reduced when silver is present. This task addressed the mirror uniformity issue.

Initial work on this task was directed toward development of a gelled electrolyte having high resistivity. In this case, uniform switching would be attained by adjusting the cell gap to make the interelectrode resistance large compared to the sheet resistance of the counter electrode. Subsequent work involved modifying the switching algorithm and cell design to provide uniform switching. Work ultimately focused on use of a resistive innerlayer in the counter electrode (or the mirror electrode) to provide interelectrode resistance to compensate for the counter electrode sheet resistance.

\subsubsection{High-Resistivity Gelled Electrolyte Development}

Initial electrolyte gellation work focused on gelling the standard GBL electrolyte (containing iodide) via ultraviolet-initiated polymerization of acrylates, which tend to be optically clear. Acrylates derived from the monomers acrylonitrile (AN), hydroxyethylmethacrylate (HEMA), hydroxyethylacrylate (HEA), and cyanoethylacrylate (CEA) were investigated. The two non-cyano-containing monomers (HEMA and HEA) precipitated the $\mathrm{Li} / \mathrm{Ag}$ salts from the GBL, whereas the cyano-containing monomers (AN and CEA) did not. The AN gel, however, tended to be hazy. An apparently stable gammabutyrolactone (GBL) gelled electrolyte $(1.0 \underline{\mathrm{M} \mathrm{LiBr}}$ and $0.75 \underline{\mathrm{M}} \mathrm{AgI})$ was attained by in situ polymerization of cyanoethylacrylate (CEA) initiated by Irgacure 651 and ultraviolet light (3:1 GBL/CEA weight ratio).

In situ gellation was accomplished for a small REM device containing GBL electrolyte (1.0 $\underline{\mathrm{M} \mathrm{LiBr}}$ and $0.75 \underline{\mathrm{M}} \mathrm{AgI})$ mixed with CEA (3:1 GBL/CEA weight ratio) and a small amount of Irgacure 651 initiator. Mirror switching was demonstrated but, after the device stood idle for a few days, large bubbles formed at the interface between the mirror electrode and the electrolyte. Significant shrinkage $(\sim 10 \%)$ of the gelled electrolyte during the curing process was also observed. Several cell fabrication approaches, including seal formation after gelling the electrolyte, were investigated to determine whether gel shrinkage during or after gellation was the cause of bubble formation, which turned out not to be the 
case. Bubble formation in such gelled electrolytes was shown to be caused by a reaction involving iodide. Numerous bubbles formed in a GBL/CEA gel containing sodium iodide, whereas no bubbles formed in a pure GBL/CEA gel. Comparative tests showed that the rate of bubble formation was decreased markedly, but was not fully suppressed, by substituting the less-nucleophilic bromide for iodide in the GBL electrolyte. These results suggested that the reaction leading to bubble formation might not occur for electrolytes based only on chloride, which is even less nucleophilic than bromide. However, the $\mathrm{LiCl}$ salt normally used is not sufficiently soluble in the GBL solvent.

An all-chloride GBL electrolyte was prepared by substituting tetrabutylammonium chloride for $\mathrm{LiCl}$ to improve the solubility of the chloride salt. A CEA-gelled GBL electrolyte containing $0.8 \underline{\mathrm{M}}$ tetrabutylammonium chloride and $0.6 \underline{\mathrm{M}} \mathrm{AgCl}$ stood for several weeks with no sign of bubbles and no apparent gel shrinkage. This electrolyte also did not crystallize when stored in a freezer at about $-20^{\circ} \mathrm{C}$ overnight.

Propylene carbonate (PC) was investigated briefly as an alternative solvent for gellation purposes, and also as a means of avoiding issues related to the controlled substance status of GBL. Propylene carbonate had previously been found to react chemically to produce gas in the presence of the lithium and silver halide salts normally used in REM devices. However, we found that PC electrolytes containing high concentrations of tetrabutylammonium chloride and silver chloride were apparently stable. A PC electrolyte containing $2.0 \underline{\mathrm{M}}$ tetrabutylammonium chloride and $1.0 \underline{\mathrm{M}} \mathrm{AgCl}$ did not evolve gas and did not crystallize when stored in a freezer at about $-20^{\circ} \mathrm{C}$ overnight. However, gas bubbles did form in the CEA-gelled electrolyte on standing. Presumably, slow PC decomposition occurs for both the liquid and gelled all-chloride PC electrolytes but bubbles form only in the gelled electrolyte, for which gas diffusion is slowed.

Gamma-valerolactone (GVL), which differs from GBL by only a methyl group, was also investigated as an alternative solvent for the all-chloride system. Commercially available GVL is relatively impure and was vacuum distilled before use.

All-chloride GBL and GVL electrolytes gelled with CEA were tested in 5-cm REM cells with dual-mirror electrodes, $2000 \AA$ silver, and acrylic tape seals. For both solvents, small bubbles formed in a line along the edge of the acrylic tape seal within a few hours, but no bubbles formed in areas away from the seal. Both cells exhibited good mirror formation and erasure but the $2000 \AA$ silver layer dissolved completely within 500 cycles. These results indicated that a reaction occurred between constituents of the acrylic tape seal and CEA (or other components of the electrolyte).

Issues associated with the all-chloride electrolyte containing $1.5 \underline{\mathrm{M} \mathrm{Et}} \mathrm{HCl}_{\mathrm{NCl}}$ and 0.75 $\underline{\mathrm{M}} \mathrm{AgCl}$ in GBL were thoroughly investigated. To eliminate the possibility that CEA impurities might be involved, distilled CEA (which is water clear instead of pale yellow) was procured. Chromatographic grade $\mathrm{Et}_{4} \mathrm{NCl}$ was also procured. Initial tests involved cells with

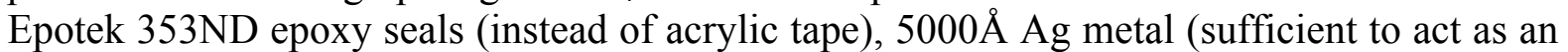
impurity getter), and both liquid and CEA-gelled electrolytes prepared with Selectipur GBL (highest purity available commercially). No bubbles formed in the vicinity of the epoxy seals 
but, despite the thick Ag metal layers and relatively pure solvent used, most of the Ag metal was lost in less than 1000 cycles. These results suggested that an impurity might be responsible for the silver loss. A likely source of high-concentration impurities is the GBL solvent, which is a major electrolyte component and may have suffered a supplier change as a result of being classified as a controlled substance. Dummying the electrolyte prior to cell assembly (via overnight electrodissolution of high-purity silver from a large-area anode coupled with silver electrodeposition on a stainless steel cathode), which should remove electroactive impurities, did not reduce silver loss in REM cells with the all-chloride electrolyte. Dummying might not remove a redox couple contaminant involving two soluble species.

Additional tests with the all-chloride electrolyte were performed using GBL purified by vacuum distillation (in house). REM cells employing Epotek epoxy and acrylic tape seals with both liquid and CEA-gelled electrolytes were cycle tested. In all cases, practically all of the $5000 \AA$ of silver was lost in less than 1000 cycles. A line of bubbles formed along the acrylic tape seal used with the gelled electrolyte, verifying the incompatibility between the CEA gelling agent and the acrylic tape. Weight loss tests at room temperature and $80^{\circ} \mathrm{C}$ showed that silver metal does not react chemically with the electrolyte. These results indicate that loss of silver for the all-chloride electrolyte is related to poor silver electrodeposit quality. Consistent with this conclusion, reasonable switching currents could not be sustained for cells with the all-chloride electrolyte, even with increased cell potential. Apparently, the large $\mathrm{Et}_{4} \mathrm{~N}^{+}$cation interferes with the silver electrodeposition process.

In the final stages of the electrolyte gellation work, we showed that stable gels can be obtained for a $\mathrm{Li}^{+}$-based all-chloride GBL electrolyte with relatively low salt concentrations $(1.0 \underline{\mathrm{M} \mathrm{LiCl}}+0.3 \underline{\mathrm{M}} \mathrm{AgCl})$ via in situ ultraviolet polymerization of acrylonitrile. This electrolyte might provide acceptable switching rates for smart window applications and avoid the problems apparently associated with the $\mathrm{Et}_{4} \mathrm{~N}^{+}$cation. Nonetheless, electrolyte gellation work was abandoned so that effort could be focused on the very attractive alternative approach of providing uniform mirror switching via a resistive electrode innerlayer.

\subsubsection{Programmed Voltage Switching}

A novel concept involving use of a dual-pulse switching voltage was investigated as a means of improving the mirror uniformity over large areas. If cathode polarization were larger than anode polarization, for example, a pulse train comprising cathodic pulses of a higher and a lower voltage would be applied. In this case, the thickness of the thicker silver deposit produced by the higher current density toward the edge of the device (near the buss bars) would be reduced by silver dissolution during the lower pulse voltage caused by excess cathode polarization produced at higher current density.

Data obtained for a dual-mirror REM cell indicated that a larger fraction of the deposited silver was dissolved for the lower cathodic voltages. In subsequent work, anode and cathode polarizations were determined separately via three-electrode potentiostatic measurements of current vs. time at various applied potentials for a clamp-on cell with a reference electrode (placed near the working electrode). The data showed that both anodic 
and cathodic polarization was small (less than $30 \mathrm{mV}$ ) even after relatively long times (100 seconds) at relatively high applied potentials $(100 \mathrm{mV})$. These results indicate that electrode concentration polarization effects would provide only a small benefit with respect to mirror uniformity.

\subsubsection{Optimum Cell Design}

Work to optimize the cell design for maximum switching uniformity of REM mirrors involved the electrode structure, buss bar placement and electrical modeling. Note that a graded cell gap could in principle be used to compensate for the counter electrode sheet resistance but would be difficult to attain for large-area devices and is not being pursued.

\subsubsection{Resistive Electrode Innerlayer}

Work to provide uniform switching over large areas focused on a novel concept involving a dot matrix counter electrode comprised of an underlayer of highly conductive ITO, an innerlayer of highly resistive material, and a thin overlayer of conductive ITO. If the resistive inner layer is graded to be thinner toward the center of the device so as to compensate for the sheet resistance of the underlayer, a constant potential (and uniform switching) can be provided over even large surfaces. For this approach, the electrolyte resistance is unimportant so that the normal REM electrolyte with proven cycle life can be used. The highly dispersed silica (HDS) gelling agent used in this electrolyte is stable under ultraviolet radiation and avoids the possibility of problems associated with unreacted monomer species. Note that the HDS gel is thixotropic so that, after shearing, it can be injected as a liquid, which forms a gel on standing. Another significant advantage of this approach is that variations in the cell gap are relatively unimportant, which simplifies device manufacturing. The feasibility of the resistive innerlayer concept depends on the availability of a transparent innerlayer material that has sufficient transparency and high cross-film resistance but does not adversely affect formation of the dot matrix electrode. For a $30-\mathrm{cm}$ wide device, a graded insulating layer should have a resistance of a few hundred ohms at the device edge. The feasibility of the resistive innerlayer approach was established by measuring resistance values of more than $100 \mathrm{ohms} / 1000 \AA$ for $\mathrm{TiO}_{2}, \mathrm{Al}_{2} \mathrm{O}_{3}$ and $\mathrm{SnO}_{2}$ innerlayers, and showing that the density of dots obtained for the dot matrix electrode is unaffected by the resistive innerlayer.

In preliminary tests, specimens consisting of various thicknesses of $\mathrm{SnO}_{2}$ on conductive ITO/glass were deposited by reactive sputtering for various times ( 1 - 35 minutes) at various gas pressures ( 1 - 5 mtorr), oxygen contents $(50-100 \%)$, and substrate temperatures $\left(120-230^{\circ} \mathrm{C}\right)$. In an attempt to measure the cross-film resistance, ac impedance spectra were obtained for each specimen with the $\mathrm{SnO}_{2}$ film in contact with an aqueous solution containing a ferro-ferricyanide redox couple (needed to minimize the interfacial charge transfer resistance). A few films were characterized optically to calibrate film thickness. Low gas pressure (1.0 mtorr) and high oxygen contents $(>75 \%)$ tended to yield very high resistances $(100 \mathrm{~K}$ ohms $)$ even for relatively thin films $(25 \mathrm{~nm})$, but the results were not very consistent. High oxygen content would be expected to increase the resistance by reducing the number of oxygen vacancies. A smooth correlation (albeit not linear) between film resistance and film thickness (deposition time) was obtained for films deposited with a 
gas pressure of 3.6 mtorr, oxygen content of about $75 \%$, and a substrate temperature of $150^{\circ} \mathrm{C}$. Measured values were $4.6 \mathrm{~K}$ ohms $(5 \mathrm{~nm}$ thickness $), 8.0 \mathrm{~K}(10 \mathrm{~nm}), 10 \mathrm{~K}(20 \mathrm{~nm}), 20 \mathrm{~K}$ $(25 \mathrm{~nm}), 50 \mathrm{~K}(50 \mathrm{~nm})$, and $340 \mathrm{~K}(150 \mathrm{~nm})$. The measured resistance was decreased by a factor of five $\left(5.0 \mathrm{~K}\right.$ for $25 \mathrm{~nm}$ film) by increasing the substrate temperature from $150^{\circ} \mathrm{C}$ to $230^{\circ} \mathrm{C}$. This is consistent with literature reports that tin oxide film resistance is decreased by heat treatment of tin oxide films under vacuum. Still the measured impedances were much higher than expected, suggesting that the measured film resistances included a contribution from the charge transfer resistance across the electrochemical interface.

After sputter deposition of a conductive ITO overlayer, ac impedance measurements in $5 \mathrm{mM}$ ferro-ferricyanide solution (including $0.5 \mathrm{M} \mathrm{NaClO} 4$ ) were repeated for specimens consisting of various thicknesses of $\mathrm{SnO}_{2}$ on conductive ITO/glass deposited by reactive sputtering at 3.6 mtorr gas pressure, $75 \%$ oxygen content and $210^{\circ} \mathrm{C}$ substrate temperature for various times (1, 2, 4 and 30 minutes). Measurements were made from 0.01 to $1000 \mathrm{~Hz}$ using a clamp-on cell $\left(0.64 \mathrm{~cm}^{2}\right.$ electrode area). At the lowest frequencies, for which resistive effects are dominant, the measured impedance for all specimens was around 100 ohms. The sharp decrease in low-frequency impedance produced by the ITO overlayer (from $10^{5}$ to $10^{2}$ ohms for the thickest $\mathrm{SnO}_{2}$ layer) could have been due to $\mathrm{SnO}_{2}$ pinholes, or to decreased charge transfer resistance for the ITO/solution interface. For ITO-coated specimens, significant contribution to the impedance from the electrochemical charge transfer resistance was demonstrated via measurements with a higher redox couple concentration (12.5 $\mathrm{mM})$, and measurements for Pt and bare ITO electrodes. Measurements at various distances away from the electrode contact showed that the ITO sheet resistance also contributed significantly to the measured impedance.

Specimens of bare ITO, ITO/ $\mathrm{SnO}_{2}\left(5-150 \mathrm{~nm} \mathrm{SnO}\right.$ thickness) and ITO/ $\mathrm{SnO}_{2}$ plated with $\mathrm{Pt}$ were examined by high-resolution SEM to detect active pinholes in the $\mathrm{SnO}_{2}$ layer that might explain the low impedances measured for ITO/ $\mathrm{SnO}_{2} / \mathrm{ITO}$ specimens. A few submicron pits were observed in the $\mathrm{SnO}_{2}$ layers and the ITO overlayers, but these did not appear to serve as nucleation sites for Pt deposition. These examinations indicated that shorting between the two ITO layers via pits in the $\mathrm{SnO}_{2}$ layer was not responsible for the decreased impedance.

Electrochemical resistance was then measured by dc voltammetry for bare ITO, ITO $/ \mathrm{SnO}_{2}$ and $\mathrm{ITO} / \mathrm{SnO}_{2} / \mathrm{ITO}$ specimens using a high ferri-ferrocyanide redox couple concentration $(50 \mathrm{mM})$ and solution stirring. A dc approach was used to preclude the possibility that the capacitive reactance associated with capacitor involving the insulating $\mathrm{SnO}_{2}$ innerlayer was sufficiently small to short out the innerlayer resistance. The results for bare ITO and the ITO/ $\mathrm{SnO}_{2} / \mathrm{ITO}$ specimens were comparable. Solution stirring decreased the resistance measured at $1 \mathrm{mV} / \mathrm{s}$ for the $\mathrm{ITO} / \mathrm{SnO}_{2} / \mathrm{ITO}$ specimen from 1600 to $200 \mathrm{ohms}$, and that for the bare ITO specimen from 1600 to 400 ohms. Resistances measured for the $\mathrm{ITO} / \mathrm{SnO}_{2}$ specimen were much larger than those for the ITO/ $\mathrm{SnO}_{2} / \mathrm{ITO}$ specimen, but not as large those measured by ac impedance at low redox couple concentration in stagnant solution (as expected). Thus, even for the higher redox couple concentration and solution stirring, electrolyte polarization effects continued to play a significant role so that an accurate measure of the $\mathrm{SnO}_{2}$ cross-film resistance was not obtained. 
Reliable measurements of innerlayer cross-film resistance were finally obtained by depositing a thin layer of platinum $(25 \AA)$ on the ITO overlayer and measuring the dc resistance by cyclic voltammetry in the standard GBL electrolyte in a clamp-on cell under nitrogen. The electrode resistance increase associated with sputtered $\mathrm{ZnO}, \mathrm{SnO}_{2}, \mathrm{TiO}_{2}$ and $\mathrm{Al}_{2} \mathrm{O}_{3}$ innerlayers sandwiched between an 20-ohm ITO underlayer and a 100-ohm ITO/Pt $(25 \AA)$ overlayer was determined by cyclic voltammetry $(50 \mathrm{mV} / \mathrm{s}$ between -0.1 and $+0.2 \mathrm{~V})$ in the standard GBL electrolyte in a clamp-on cell $\left(0.64 \mathrm{~cm}^{2}\right)$ under nitrogen. Electrode resistance was determined from the voltammetric slopes in the cathodic region since those in the anodic region tended to be more variable and somewhat lower, presumably due to greater concentration polarization.

Table 1 summarizes the data for the total electrode resistance and the innerlayer resistance (total resistance minus the resistance measured for the ITO/Pt substrate). Values given are the average of two measurements (generally comparable). Three of the innerlayer materials $\left(\mathrm{SnO}_{2}, \mathrm{TiO}_{2}\right.$ and $\left.\mathrm{Al}_{2} \mathrm{O}_{3}\right)$ provided more than $100 \mathrm{ohms} / 1000 \AA$ of resistance (based on the thicker films for which the data are more reliable). These data show that thin innerlayers of wide-bandgap oxides can provide the resistance needed for uniform switching of large-area REM devices.

Table 1

Measured Resistance for Various Electrode Innerlayer Materials

\begin{tabular}{|l|c|c|c|}
\hline Innerlayer & Thickness & \multicolumn{2}{|c|}{ Average Resistance (ohm/cm ${ }^{2}$ ) } \\
\cline { 3 - 4 } & $(\mathbf{A})$ & Total & Innerlayer \\
\hline \hline None & & 71 & \\
\hline $\mathrm{ZnO}$ & 300 & 112 & 40 \\
$\mathrm{ZnO}$ & 1000 & 117 & 46 \\
$\mathrm{ZnO}$ & 3000 & 146 & 75 \\
\hline $\mathrm{SnO}$ & 230 & 77 & 6 \\
$\mathrm{SnO}_{2}$ & 470 & 96 & 24 \\
$\mathrm{SnO}_{2}$ & 700 & 114 & 43 \\
$\mathrm{SnO}_{2}$ & 1400 & 154 & 82 \\
\hline $\mathrm{TiO}_{2}$ & 500 & 131 & 60 \\
$\mathrm{TiO}_{2}$ & 1000 & 207 & 136 \\
$\mathrm{TiO}_{2}$ & 3000 & 349 & 278 \\
\hline $\mathrm{Al}_{2} \mathrm{O}_{3}$ & 300 & 260 & 188 \\
$\mathrm{Al}_{2} \mathrm{O}_{3}$ & 2500 & 432 & 361 \\
\hline
\end{tabular}

The second key issue with respect to the feasibility of using a resistive innerlayer to provide uniform mirror switching was also addressed. As shown in Table 2, Pt dot densities of 2.2 and 1.9 million $/ \mathrm{cm}^{2}$ were obtained by plating at $-0.45 \mathrm{~V}$ for 5 minutes ( $\mathrm{pH} 11.5 \mathrm{bath}$ ) on 100-ohm ITO overlayers on 5-nm and 20-nm thick $\mathrm{SnO}_{2}$ innerlayers, respectively (on 20ohm ITO underlayers). These values are within the density range $\left(1-3 \mathrm{million} / \mathrm{cm}^{2}\right)$ normally obtained for thicker ITO layers on glass substrates (see Section 4.3), indicating that the thin ITO overlayers can be used to form dot matrix electrodes. Such overlayers with a

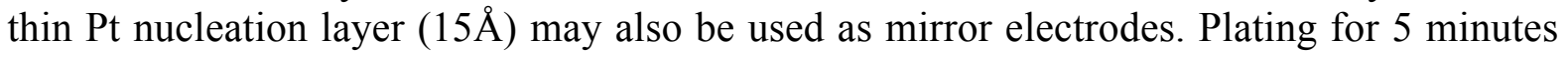
directly on thin $\mathrm{SnO}_{2}$ layers gave dots of diameters somewhat larger than those normally 
obtained for ITO $(1.3-1.4 \mu \mathrm{m})$ but very low dot densities. Plating at $-0.45 \mathrm{~V}$ directly on the relatively thick layer of $\mathrm{SnO}_{2}(150 \mathrm{~nm})$ proceeded slowly but after 30 minutes yielded a bimodal array of large dots $(5.6 \mu \mathrm{m}$ diameter $)$ of low density $\left(0.03 \mathrm{million} / \mathrm{cm}^{2}\right)$, and small dots $(0.4 \mu \mathrm{m}$ diameter $)$ of higher density $\left(1.1 \mathrm{million} / \mathrm{cm}^{2}\right)$.

Table 2

Plated Pt Dot Density and Size for ITO Electrodes with Resistive Innerlayers

\begin{tabular}{|c|c|c|c|c|c|c|c|c|}
\hline \multirow{3}{*}{$\begin{array}{l}\text { Ref. } \\
\text { No. }\end{array}$} & \multirow{3}{*}{$\begin{array}{l}\text { Specimen } \\
\text { No. }\end{array}$} & \multirow{3}{*}{$\begin{array}{l}\mathrm{SnO}_{2} \\
\text { Thickness } \\
\text { (nm) }\end{array}$} & \multicolumn{2}{|c|}{ Pt Plating } & \multicolumn{4}{|c|}{ Pt Dot Density and Diameter } \\
\hline & & & \multirow[b]{2}{*}{ (V) } & \multirow[b]{2}{*}{$(\min )}$. & \multicolumn{2}{|c|}{$\mathrm{SnO}_{2}$ Innerlayer } & \multicolumn{2}{|c|}{ ITO Overlayer } \\
\hline & & & & & $\left(\right.$ million $\left./ \mathrm{cm}^{2}\right)$ & $(\mu \mathrm{m})$ & $\left(\mathrm{million} / \mathrm{cm}^{2}\right)$ & $(\mu \mathrm{m})$ \\
\hline 145 & M3154C & 20 & -0.45 & 5 & 0.032 & 1.9 & 2.4 & 1.5 \\
\hline 146 & M3154F & 5 & -0.45 & 5 & 0.037 & 2.2 & 2.4 & 1.5 \\
\hline 147 & M3104A & 140 & -0.45 & 30 & $\begin{array}{l}0.03 \\
1.1\end{array}$ & $\begin{array}{l}5.6 \\
0.4\end{array}$ & & \\
\hline 148 & M3104C & 20 & -0.45 & 5 & 0.42 & 2.0 & & \\
\hline
\end{tabular}

\subsubsection{Gelled Electrolyte Considerations}

Optical and physical considerations with respect to the HDS-gelled electrolyte were also addressed. The refractive index of the GBL electrolyte was measured to be 1.51, which is close to those of soda lime glass (1.51) and quartz (1.46). Refractive index measurements on electrolytes with various salt concentrations showed that even this slight index mismatch (0.05) between the electrolyte and HDS could be eliminated by reducing the AgI concentration in the electrolyte from $1.5 \underline{\mathrm{M}}$ to about $0.5 \underline{\mathrm{M}}$, albeit with a concomitant decrease in current carrying capability and switching speed.

The optical quality of REM transmissive cells is apparently not adversely affected by the slight refractive index mismatch between the standard GBL electrolyte and the HDS gelling agent (silica). A $10-\mathrm{cm}$ square dummy REM device $(0.4 \mathrm{~mm}$ cell gap) was constructed with the normal mirror electrode and a bare ITO counter electrode so that the effects of the gelled electrolyte (8\% HDS) on the optical characteristics could be ascertained. The bare counter electrode precluded switching the device but mimicked the characteristics of a dot matrix counter electrode (without the dots). The electrolyte was visually very clear, and both near and far objects viewed through the cell had a sharp appearance. Gelled electrolytes in actual REM cells also appear very clear to the eye. The visual consequences of using HDS as a gelling agent in REM cells with the standard GBL electrolyte appear to be insignificant.

The HDS-gelled electrolyte also does not melt or undergo syneresis at elevated temperatures. A GBL electrolyte with $8 \%$ HDS was shown to remain solid with no sign of expelled liquid after 5 days at $80^{\circ} \mathrm{C}$ (in a capped vial). 


\subsubsection{Electrical Modeling}

Figure 2 illustrates the electrical model and equivalent circuit used to define the cell geometry and electrode structures providing optimum mirror switching uniformity. For the model, two series of resistors represent the sheet resistances of the two REM electrodes, which are divided in segments connected via resistors representing the sum of the electrolyte resistance and the innerlayer resistance. The arrangement depicted in Fig. 2 has one buss bar for each electrode, on opposite sides of the cell. For this staggered buss bar arrangement, the sheet resistances for the two electrodes tend to cancel each other out. Of course, this is only an approximation, especially since the sheet resistance of the mirror electrode varies depending on the amount of silver present as a mirror deposit.
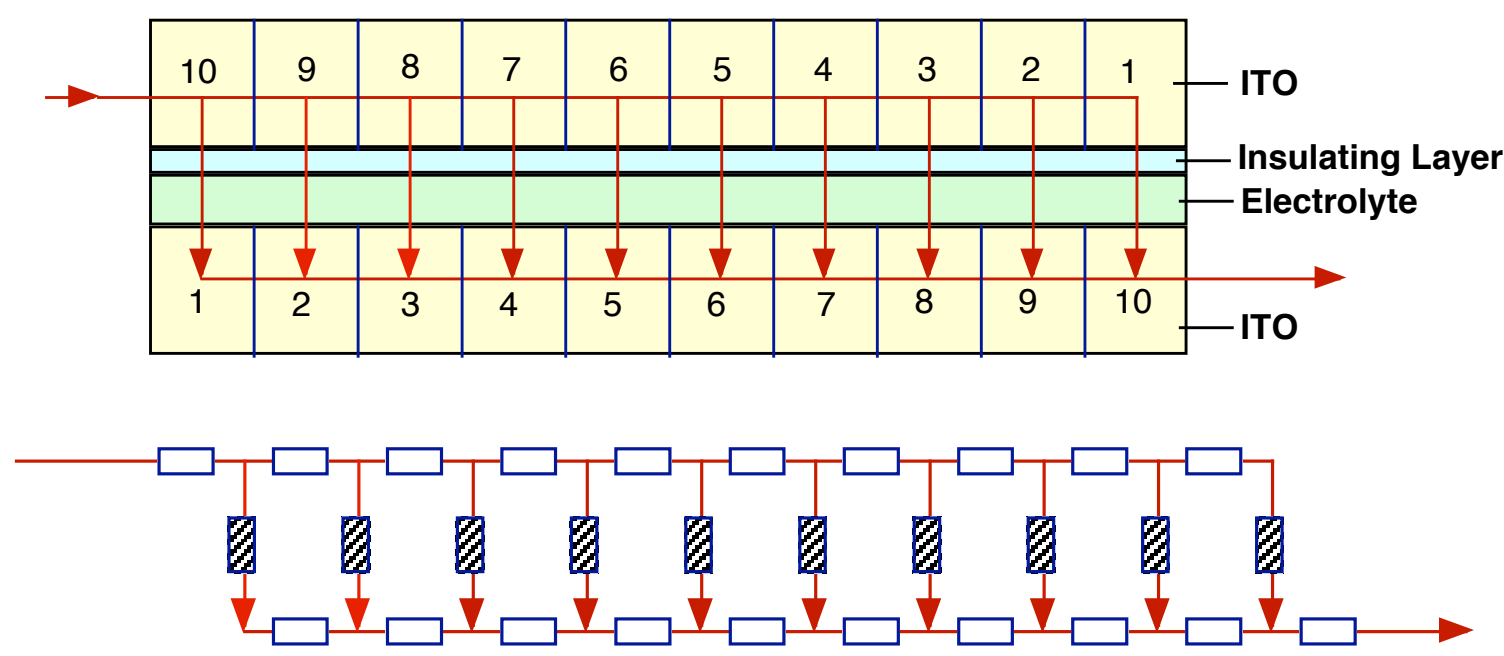

Fig. 2 Model and equivalent circuit for REM cell.

A preliminary modeling run was made using the equivalent circuit shown in Fig. 3 for a 10-cm cell having staggered bus bars, a constant counter electrode sheet resistance of 5 $\mathrm{ohm} / \mathrm{square}$, a mirror electrode sheet resistance varying from 5 to $0.1 \mathrm{ohm} / \mathrm{square}$ (due to silver deposition), and an interelectrode resistance varied over the range from 175 to 312 ohms (via a graded interlayer). For this equivalent circuit, the model predicts, as illustrated in Fig. 4, that the current distribution will tend to average out as the mirror electrode sheet resistance changes, being uniform for an intermediate sheet resistance value.

It was later found that a simpler modeling approach based on the assumption of a uniform current distribution over the electrode surface provided more useful results. In this case, the voltage drop produced by the electrode sheet resistance can be calculated at every point along the electrode, directly yielding the compensation that must be provided by the graded innerlayer resistance at every point. Since the current passing through a given area of the electrode sheet decreases toward the center of the electrode (away from the buss bars), the required resistance compensation tends to flatten out near the center of the electrode. 


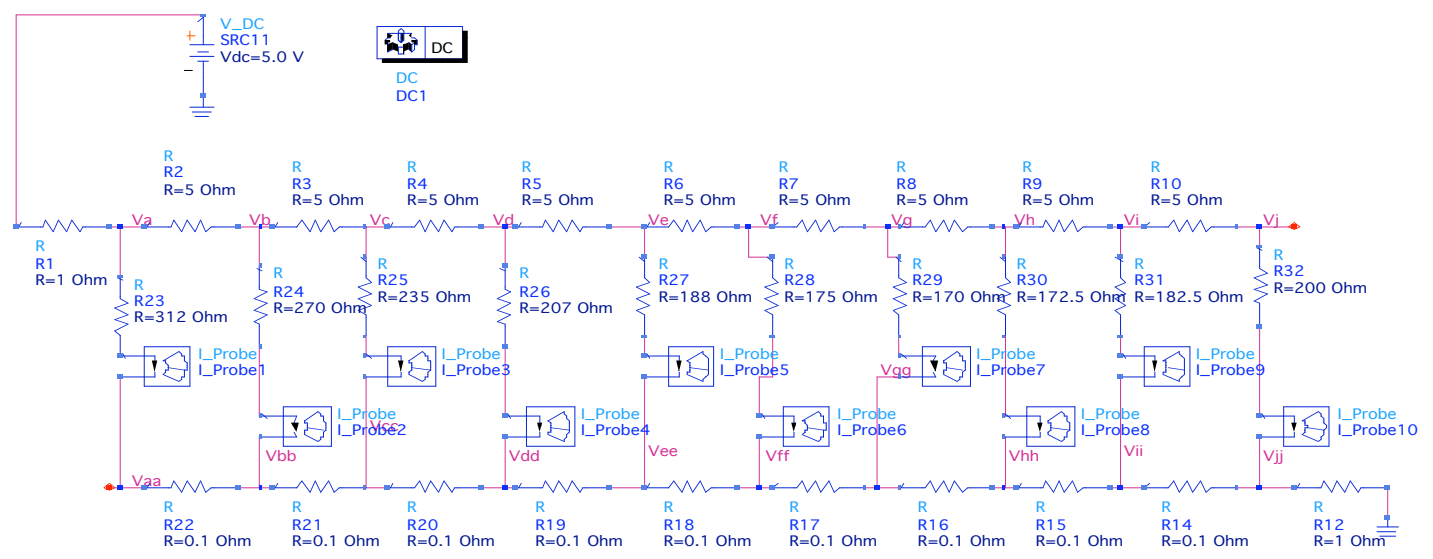

Fig. 3 Equivalent circuit of cell for preliminary modeling run.

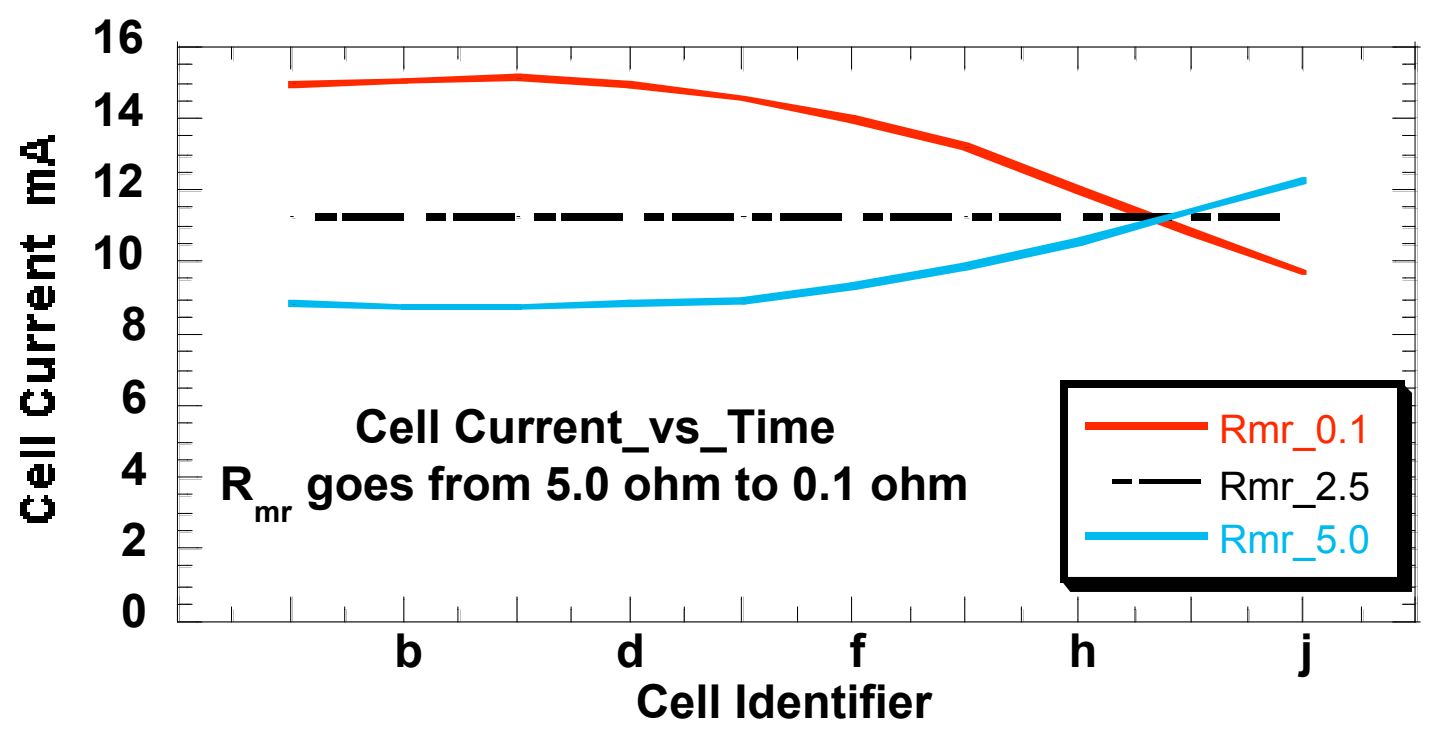

Fig. 4 Current distribution for different electrode sheet resistances for Fig. 3 cell. 


\subsection{Edge Seal Development}

Work on this task focused on heat-cured and ultraviolet-cured epoxies selected in collaboration with suppliers (Masterbond, Addison Clear-Wave, Tech-Film, 3-M, Ellsworth Adhesive, and Emmerson \& Cumming) or provided by Gentex (as sealed cells). Of the 20 materials evaluated, only 4 passed preliminary tests based on specimen appearance, adhesion to glass, weight change and bond strength (lap joint between two glass slides) after exposure to the GBL electrolyte. Further tests were performed on the four promising sealants identified in-house, and on two seal technologies provided by Gentex. These tests included measurements of silver loss for REM cells with dual mirror electrodes (ITO/15 $\mathrm{At}$ ) as a function of time at room temperature in air and under nitrogen (without cycling), as a function of time at $80^{\circ} \mathrm{C}$ in air (without cycling), and during cycling in air at room temperature. Dual mirror electrodes were used to limit the sources of silver loss. The Gentex cells were $10-\mathrm{cm}$ square with standard liquid electrolyte (Aldrich GBL) and had seals formed directly to the ITO surface (edges were masked during deposition of silver layer). Except for the EC286 seal for Cell D155, other seals were formed to the silver layer on the mirror electrode (edges not masked during silver deposition) and were tested in 5-cm square cells assembled with 1-mm glass sheet spacers and the standard HDS-gelled electrolyte $(10 \% \mathrm{M}-$ 5). Cell cycling involved transfer of $400 \AA$ silver at $3.5 \mathrm{~mA} / \mathrm{cm}^{2}$ on each cycle. Silver loss was periodically determined by measuring the charge required for transfer of all of the silver from one electrode to the other. A seal provided by Gentex was shown to exhibit the oxygen barrier properties and stability needed for long-term operation in REM cells. Measured silver loss rates were $0.9 \AA$ /day after 84 days at room temperature under nitrogen, $0.3 \AA$ /day after 85 days at room temperature in air and $1.0 \AA$ /day after 77 days at $80^{\circ} \mathrm{C}$ in air, all of which are within the noise. Two promising alternative seal materials (OE188 and EC286) were identified. The EC286 seal has been shown to be effective at $80^{\circ} \mathrm{C}$ with the caveat that a better procedure is needed at RSC for plugging the fill hole.

Some early lessons were learned from the initial cell cycle tests. The commercial Selectipur GBL solvent, for which high-purity is claimed, contains contaminants that react directly with silver to produce rapid initial silver loss (within the first few thousand cycles), and apparently cause longer-term silver loss after $12 \mathrm{~K}$ to $14 \mathrm{~K}$ cycles (presumably via a redox process). Such contaminants might not be present in the Aldrich GBL used for Gentex cells, which did not exhibit rapid initial Ag loss. It was necessary to vacuum distill the Selectipur GBL to obtain meaningful results. Another lesson learned was that silver tends to redistribute on the electrodes during cycling with liquid electrolytes, presumably due to electrolyte convection caused by local electrolyte density changes during silver plating and erasure. Such silver redistribution results in increasingly nonuniform current distribution, which accelerates silver loss during cell cycling. All RSC cells contained HDS-gelled electrolyte made with vacuum distilled GBL, which prevented silver redistribution and minimized contaminant effects.

Figure 5 shows a plot of silver loss versus the number of harsh cycles in air for a cell with the acrylic tape seal previously used for REM development work. For harsh cycles, voltage was applied to the mirror electrode for an additional 10 seconds after mirror erasure. In previous studies with unpurified GBL electrolytes, harsh cycles for cells with acrylic tape 
seals degraded $15 \AA$ Pt nucleation layers and produced hazy deposits near the acrylic tape after about $10 \mathrm{~K}$ cycles. Such nucleation layer degradation also occurred around acrylic tape placed in the center of the cell, demonstrating that contaminants from the acrylic tape played a role. For the cell of Fig. 5, no nucleation layer degradation occurred up to $70 \mathrm{~K}$ harsh cycles, suggesting that electrolyte contaminants (from the unpurified GBL used in previous work) also played a role in nucleation layer degradation. The silver loss rate $(40 \AA / \mathrm{Kcycle})$ is much too high for practical use. Normal cell cycling (without the additional 10 seconds after mirror erasure) was used for all other tests. The silver loss rate during normal cycling for a cell with the acrylic tape seal was $24 \AA / \mathrm{Kcycle}$, which is still far to high for practical use.

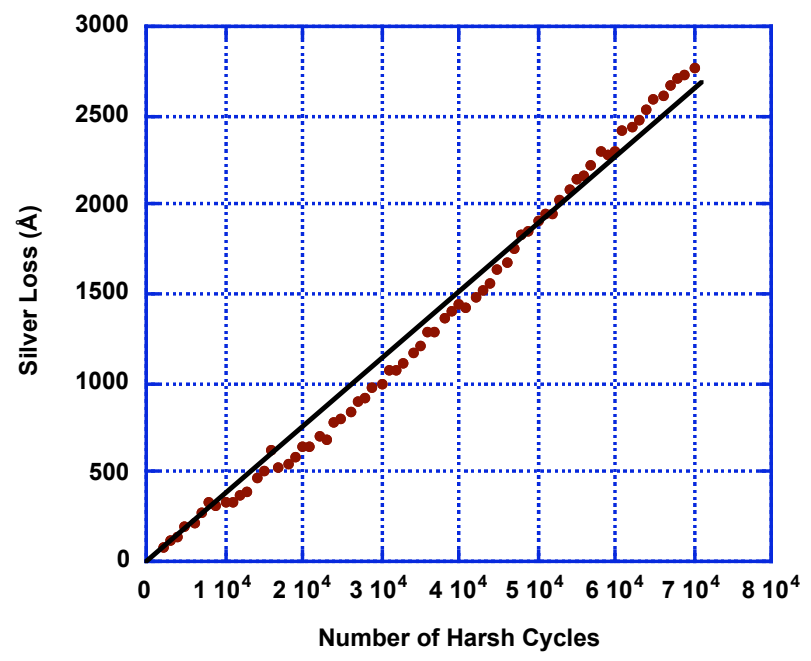

Fig. 5 Silver loss during cycling of a cell with acrylic tape seal in air.

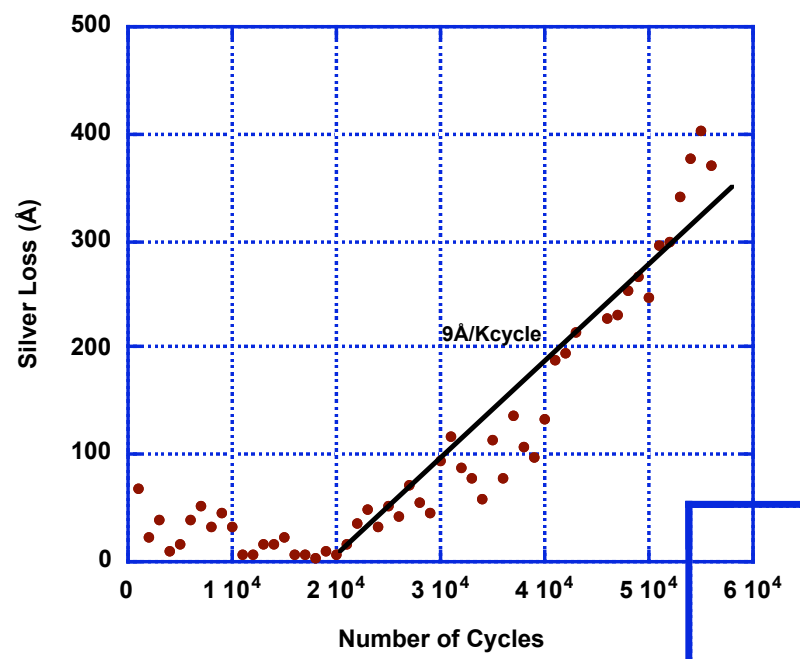

Fig. 6 Silver loss during cycling of a cell with an Oxy-Bond 109 seal in air. 
Figure 6 shows a plot of silver loss versus the number of normal cycles in air for a cell with the Oxy-Bond 109 seal. Silver loss in this case is negligible (within the noise) up to about $20 \mathrm{~K}$ cycles, then increases to $9 \AA /$ Kcycle. This behavior is typical of that observed for cells with other seals, for which silver loss tended to increase after $20 \mathrm{~K}$ to $40 \mathrm{~K}$ cycles. Such increases are apparently due to electrode polarization resulting from a chemical imbalance in the electrolyte caused by continuous cycling. One possibility is that local concentration changes in the electrolyte result in localized film formation, which increases the current density on other areas of the electrode.

Figure 7 shows a plot of silver loss versus the number of cycles in air for a cell before and after removal of 60 -second pauses between plate-erase half cycles. The substantial increase in the silver loss rate (from 6 to $25 \AA / K c y c l e$ ) supports the premise that continuous cycling artificially increases the rate of silver loss.

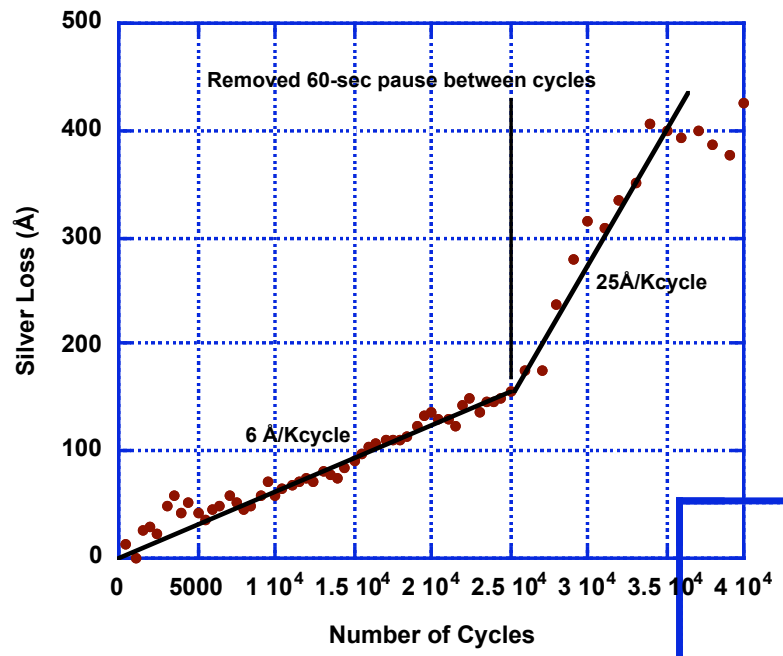

Fig. 7 Silver loss during cycling of a cell (Epotek OE188 seal) in air before and after removal of 60-second pauses between plate-erase half cycles.

Table 3 summarizes the edge seal cycle test results. In addition to the final value, silver loss measured at $1 \mathrm{~K}$ cycle is also given since a relatively large amount of silver tended to be lost initially, presumably by reaction with impurities from the epoxy seal. Silver loss rates were determined graphically from graphs of silver loss versus number of cycles. The initial silver loss rates for the 3M 460, OB 109, GEN-1 and Epotek 353ND seals were negligible (within the noise). As discussed above, the appreciable silver loss rates for these seals beginning at $20 \mathrm{~K}$ to $30 \mathrm{~K}$ cycles is apparently due to an electrolyte chemical imbalance caused by continuous cycling. Oxygen intrusion through the seal as indicated by appreciable initial silver loss rates $(10-12 \AA /$ Kcycle for the Epotex OE188 seal and $24 \AA / K c y c l e$ for the acrylic tape seal) apparently delays the electrolyte imbalance (to $40 \mathrm{~K}$ cycles for the OE188 
seal and $>60 \mathrm{~K}$ cycles for acrylic tape seal). These results show that silver loss due to oxygen intrusion at room temperature is negligible for the 3M 460, OB 109, GEN-1 and Epotek 353ND seals. All of the epoxy seals performed better than acrylic tape. Subsequently obtained data indicated that the Epotek OE188 epoxy is also a good oxygen barrier at room temperature but provided inconsistent results because the seal curing process was not well controlled. Note that the OE188 epoxy should be the same formulation as the 353ND epoxy with a filler added. These data also show that inherent silver loss due to cell cycling is negligible.

Table 3

Silver Loss for Dual-Mirror Cells during Cycling in Air at Room Temperature

\begin{tabular}{|l|l|l|l|l|l|l|}
\hline Cell. No. & Seal Type & $\begin{array}{l}\text { No. Cycles } \\
\text { (K cycles) }\end{array}$ & $\begin{array}{l}\text { Ag Loss } \\
(\mathbf{A})\end{array}$ & \multicolumn{2}{|l|}{ Ag Loss Rate (Å/Kcycle) } \\
\cline { 3 - 7 } & & Initial & Final \\
\hline D81 & Acrylic Tape & $\begin{array}{l}1 \mathrm{~K} \\
60 \mathrm{~K}\end{array}$ & $\begin{array}{l}7 \\
1882\end{array}$ & 24 & 24 \\
\hline D65 & OE188 & $\begin{array}{l}1 \mathrm{~K} \\
50 \mathrm{~K} \\
1 \mathrm{~K}\end{array}$ & $\begin{array}{l}104 \\
938 \\
0\end{array}$ & 12 & $40(>40 \mathrm{~K})$ \\
D102 & OE188 & $24 \mathrm{~K}$ & 229 & 10 & 10 \\
\hline D77 & EC 286 & $\begin{array}{l}1 \mathrm{~K} \\
89 \mathrm{~K}\end{array}$ & $\begin{array}{l}1 \\
848\end{array}$ & 9 & 9 \\
\hline D73 & $3 \mathrm{M} 460$ & $\begin{array}{l}1 \mathrm{~K} \\
89 \mathrm{~K}\end{array}$ & $\begin{array}{l}404 \\
1289\end{array}$ & 0 & $14(>20 \mathrm{~K})$ \\
\hline D69 & OB 109 & $\begin{array}{l}1 \mathrm{~K} \\
56 \mathrm{~K}\end{array}$ & $\begin{array}{l}68 \\
370\end{array}$ & 0 & $9(>20 \mathrm{~K})$ \\
\hline G1a & GEN-1 & $\begin{array}{l}1 \mathrm{~K} \\
47.5\end{array}$ & $\begin{array}{l}81 \\
375\end{array}$ & 2 & $16(>30 \mathrm{~K})$ \\
\hline D85 & $353 N D$ & $\begin{array}{l}1 \mathrm{~K} \\
64 \mathrm{~K}\end{array}$ & $\begin{array}{l}70 \\
1343\end{array}$ & 0 & $35(>25 \mathrm{~K})$ \\
\hline
\end{tabular}

Table 4 summarizes the silver loss data for cells with various seal materials during standing at open circuit under nitrogen (room temperature) and in air (room temperature and $80^{\circ} \mathrm{C}$ ). Note that silver losses of $1 \AA$ /day or less are within the noise. The results may be summarized as follows:

- Outstanding results were obtained for the Gentex seals, especially the Gen-1 material. Silver losses were $76 \AA$ (only $1.0 \AA$ /day) for the Gen- 1 seal after 77 days at $80^{\circ} \mathrm{C}$ in air, and $411 \AA$ (5.3 $\AA$ /day) for the Gentex-2 seal under the same conditions. Except for $3 \mathrm{M}$

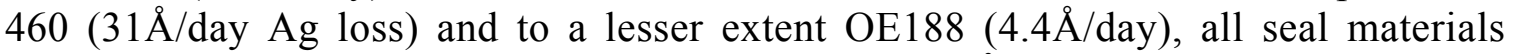
performed reasonably well in air at room temperature (1.2 $\AA$ /day or less).

- Cells with the baseline acrylic tape seal did not lose Ag on standing at room temperature although previous results showed that such cells do lose Ag during cycling at room temperature in air. Acrylic tape cells rapidly lost $\mathrm{Ag}$ at $80^{\circ} \mathrm{C}$ in air.

- All of the epoxy materials, except 3M 460, provided a good oxygen barrier at room temperature. The relatively high silver loss rate for the OE188 seal in air at room

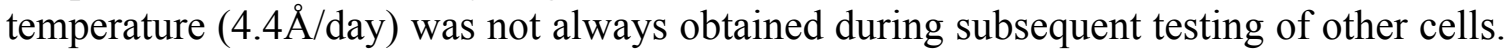
It appears that better procedures are needed for processing/curing the OE188 material. 
- Except the EC286 seal in Cell D155, all of the epoxy seals failed catastrophically within 10 days at $80^{\circ} \mathrm{C}$, i.e., popped open or formed a large bubble. This apparently resulted from loss of adhesion to the silver layer since the seal for Cell D155, which was made directly to the ITO/Pt layer, was apparently stable at $80^{\circ} \mathrm{C}$. For the latter cell, significant silver loss occurred only after 3 days at $80^{\circ} \mathrm{C}$ and coincided with formation of a bubble near the hole used to inject the electrolyte into the cell. The epoxy used to seal the fill hole apparently did not fully cure in contact with the electrolyte (at room temperature). In production, the fill hole epoxy would be rapidly cured using highly-focused intense light (and the heat generated). These results indicate that the EC286 epoxy would be a viable seal material, in conjunction with an improved procedure for sealing the fill hole. Some of the other epoxies tested might also give acceptable results if the seal were made directly to the ITO layer, rather than to the silver layer. Note that the accelerated test temperature $\left(80^{\circ} \mathrm{C}\right)$ was chosen arbitrarily and may be too high for use as a long-term accelerated test. In practice, devices would be subjected to such temperatures only briefly.

Table 4

Edge Seal Open Circuit Test Results

\begin{tabular}{|c|c|c|c|c|c|c|}
\hline $\begin{array}{l}\text { Cell } \\
\text { No. }\end{array}$ & Seal Type & \begin{tabular}{|l|} 
Test \\
Conditions
\end{tabular} & \begin{tabular}{|l} 
Time \\
(Days)
\end{tabular} & $\begin{array}{l}\text { Ag Loss } \\
(\AA)\end{array}$ & $\begin{array}{l}\text { Ag Loss Rate } \\
\text { (A/Day) }\end{array}$ & $\begin{array}{l}\text { Comments/ } \\
\text { Failure Mode }\end{array}$ \\
\hline D78 & Tape & Nitrogen & 70 & 67 & 1.0 & \\
\hline D79 & Tape & Air (RT) & 70 & 62 & 0.9 & \\
\hline D80 & Tape & Air $\left(80^{\circ} \mathrm{C}\right)$ & 21 & 2026 & 96 & Ag Gone \\
\hline G1c & Gen-1 & Nitrogen & 84 & 72 & 0.9 & Aldrich GBL \\
\hline G1a & Gen-1 & Air (RT) & 85 & 24 & 0.3 & Aldrich GBL \\
\hline $\mathrm{G} 1 \mathrm{~b}$ & Gen-1 & Air $\left(80^{\circ} \mathrm{C}\right)$ & 77 & 76 & 1.0 & Aldrich GBL \\
\hline G2d & Gen-2 & Nitrogen & 77 & 229 & 3.0 & Aldrich GBL \\
\hline G2c & Gen-2 & Air (RT) & 84 & 126 & 1.5 & Aldrich GBL \\
\hline G2b & Gen-2 & $\operatorname{Air}\left(80^{\circ} \mathrm{C}\right)$ & 77 & 411 & 5.3 & Aldrich GBL \\
\hline D97 & $353 N D$ & Nitrogen & 68 & 4 & 0.1 & \\
\hline $\begin{array}{l}\text { D103 } \\
\text { D84 }\end{array}$ & $\begin{array}{l}353 N D \\
353 N D\end{array}$ & $\begin{array}{l}\text { Air (RT) } \\
\text { Air }\left(80^{\circ} \mathrm{C}\right)\end{array}$ & $\begin{array}{l}49 \\
45\end{array}$ & $\begin{array}{l}21 \\
1231\end{array}$ & $\begin{array}{l}0.4 \\
27\end{array}$ & \\
\hline D62 & OE188 & Nitrogen & 70 & 46 & 0.7 & \\
\hline D63 & OE188 & Air (RT) & 71 & 313 & 4.4 & \\
\hline D107 & OE188 & Air $\left(80^{\circ} \mathrm{C}\right)$ & 7 & 56 & 8.0 & Popped Open \\
\hline D54 & EC286 & Nitrogen & 70 & 0 & 0.0 & \\
\hline D75 & EC286 & Air (RT) & 71 & 31 & 0.4 & \\
\hline D76 & EC286 & Air $\left(80^{\circ} \mathrm{C}\right)$ & 10 & 706 & 71 & Popped Open \\
\hline D155 & EC286 & Air $\left(80^{\circ} \mathrm{C}\right)$ & $\begin{array}{l}3 \\
8\end{array}$ & $\begin{array}{l}0 \\
111\end{array}$ & $\begin{array}{l}0 \\
22\end{array}$ & $\begin{array}{c}\text { Bubble Growing } \\
\text { at Fill Hole }\end{array}$ \\
\hline D66 & OB109 & Nitrogen & 70 & 85 & 1.2 & \\
\hline D67 & OB109 & Air (RT) & 70 & 81 & 1.2 & \\
\hline D68 & OB109 & Air $\left(80^{\circ} \mathrm{C}\right)$ & 3 & 1840 & 610 & Huge Bubble \\
\hline D70 & $3 \mathrm{M} 460$ & Nitrogen & 70 & 132 & 1.9 & \\
\hline D71 & $3 \mathrm{M} 460$ & Air (RT) & 63 & 1981 & 31 & \\
\hline D72 & $3 \mathrm{M} 460$ & Air $\left(80^{\circ} \mathrm{C}\right)$ & 3 & 1763 & 590 & Huge Bubble \\
\hline
\end{tabular}


As part of the work to minimize silver loss in cells with dot matrix electrodes (Section 4.3.3), improved procedures for forming EC286 seals were developed. The improved seal formation sequence included: thoroughly mixing Part A and Part B $(1.0 / 1.8$ by weight) of the epoxy; adding $25 \mathrm{wt} \%$ (instead of $50 \mathrm{wt} \%)$ glass beads $(0.5$ $0.8 \mathrm{~mm}$ Q-Beads); again thoroughly mixing the epoxy; applying a line of epoxy along the perimeter of the cell; heating 3 hours (instead of 2 hours) at $65^{\circ} \mathrm{C}$ in air; letting the cell stand overnight; heating 90 minutes (instead of $30-45$ minutes) at $80^{\circ} \mathrm{C}$ in air; and evacuating the cell before filling. Seals formed by the improved procedures exhibited significantly less silver loss.

The optimum glass bead loading for the OE188 seal was determined by applying lines of the OE188 epoxy with 20,35, 50 and $75 \mathrm{wt} \%$ glass bead loading between glass slides and curing the epoxy at $80^{\circ} \mathrm{C}$. Optimum results in terms of minimal epoxy oozing and ease of handling were observed for the $50 \%$ loading. For preliminary tests to determine an appropriate OE188 cure temperature, OE188 seals (50\% glass beads) were incorporated in dummy cells (glass panes only) and cured at various temperatures (80, 100,120 and $140^{\circ} \mathrm{C}$ ). The dummy cells were baked at $80^{\circ} \mathrm{C}$ and monitored for degradation. No discoloration, disbonding or bubble formation was observed for any of these cells.

\subsection{Counter Electrode Development}

Work to develop a manufacturable counter electrode focused on electrodepositing micron-sized islands of platinum at inherent active sites on a continuous layer of ITO transparent conductor. The optimum density of platinum islands $\left(1-3 \mathrm{million} / \mathrm{cm}^{2}\right)$ was consistently attained via use of a commercial alkaline plating bath. The island density is very insensitive to ITO sputtering variables and etching treatments, making the electrode fabrication process robust and amenable to large-scale use. In addition, the feasibility of an alternative REM counter electrode based on a conducting polymer was demonstrated.

\subsubsection{Dot Matrix Electrode Concept}

Figure 8 depicts a dot matrix counter electrode comprised of a continuous layer of transparent conductor (ITO or FTO) with ultra-small islands of electrodeposited silver on noble metal nuclei distributed uniformly but randomly in a dot matrix over the surface. During mirror erasure to increase device transmission, silver electrodeposition occurs preferentially on the silver/noble metal islands because of the higher voltage required for deposition on the transparent oxide conductor, which serves as a current collector. Spherical diffusion of silver ions to such fine nucleation sites provides much higher current carrying capability (compared to planar diffusion to larger grid lines of the same total cross-sectional area), and results in nearly spherical silver deposits. Such Pt/Ag micro-spheres have a surface area that is 4 times the cross-sectional area and thus provide an optimal tradeoff between fast mirror switching and high maximum light transmission. This dot matrix approach will enable low-cost production of efficient counter electrodes for large-area REM smart window devices. 


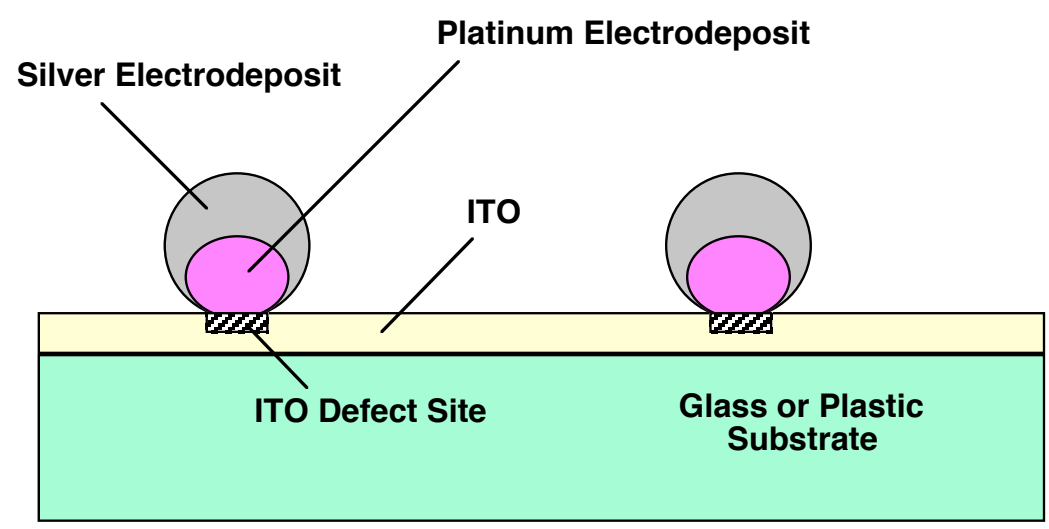

Fig. 8 Schematic of dot matrix counter electrode.

Dot matrix counter electrodes may be fabricated without photolithography by preferential electrodeposition of noble metal nuclei at active sites on the transparent conductor surface, which occurs at a lower cathodic voltage than deposition on the bulk material. Silver and platinum both deposit preferentially at active sites on ITO and FTO substrates. The active sites are present at relatively low density so that silver deposits produced at moderate voltages on bare ITO and FTO are not visible to the naked eye even after passage of an amount of charge that would yield a highly reflective mirror on a uniformly platinized surface. Silver electrodeposition on bare ITO and FTO is irreversible in the sense that the deposit is not readily stripped anodically from the surface (slow rather than fast decay in the anodic stripping current) and some of the deposited silver is permanently lost (less charge required for stripping than for plating). On the other hand, silver electrodeposition on Pt nuclei deposited at active sites on ITO and FTO surfaces has been shown to be reversible. An important element of the approach for the proposed project is electrodeposition of noble metal nuclei on the FTO/ITO active sites so that they become part of the dot matrix counter electrode, effectively suppressing irreversible electrodeposition of silver that would otherwise occur at such active sites.

\subsubsection{Dot Matrix Electrode Fabrication}

Work under this task showed that plating sputtered ITO material from a $\mathrm{pH} 11.5$ platinum bath at constant potential provides a matrix of Pt dots of the optimum density (1 - 3 million dots $/ \mathrm{cm}^{2}$ ) and relatively uniform distribution. Lines of high-density dots observed in initial runs were eliminated by omitting the machine-washing step in the ITO deposition process. Rapid decreases in the current for dot matrix electrodes tested in sealess cells with the standard GBL electrolyte were eliminated by purifying the GBL solvent (via distillation). Good current carrying capability was demonstrated for optimized dot matrix electrodes. Extraneous silver deposition on exposed ITO was shown to be effectively suppressed by limiting the plating potential of the dot matrix electrode, and/or treating the exposed ITO via oxygen plasma or heating in air. Oxygen plasma is preferred since heat treatment in air tends to increase the sheet resistance of the ITO layer. Silver loss due to exposed ITO seems to be self-limited by passivation during cell cycling. 


\subsubsection{Substrate Material Selection}

Initial work under this subtask determined the platinum plating conditions to be used for comparing ITO materials from various suppliers. Dot matrix specimens were prepared by depositing Pt nuclei on ITO (Donnelly) at constant potential from a commercial (Technic) Pt

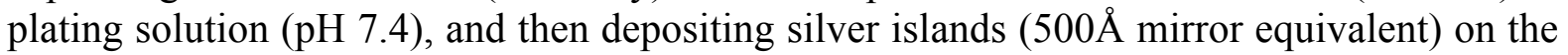
Pt nuclei from the GBL electrolyte $(-0.1 \mathrm{~V})$. Measurements of island density and uniformity were made via SEM micrographs for potentials of $-0.15,-0.3,-0.45,-0.75$ and $-1.0 \mathrm{~V}$ vs. SCE, and times of 1 - 5 minutes and 2 - 4 hours (lower potentials). The data are summarized in Table 5. Island densities for Pt deposition times in the minute range were about $10^{3} / \mathrm{cm}^{2}$ and were practically independent of potential below $-0.5 \mathrm{~V}$ but were much higher at more negative potentials (about $10^{8} / \mathrm{cm}^{2}$ at $-1.0 \mathrm{~V}$ ). Subsequent work focused on the less negative potential range, for which progressive nucleation is minimized and results were expected to be more consistent, especially over large areas.

Table 5

Potential and Time Effects on Pt Nuclei Density

\begin{tabular}{|c|c|c|c|c|c|c|c|}
\hline \multicolumn{2}{|c|}{ ITO } & \multicolumn{4}{|c|}{ Pt Plating } & \multicolumn{2}{|c|}{ Dot Density $/ \mathrm{cm}^{2}$} \\
\hline ITO & $\begin{array}{c}\text { Ohm/ } \\
\text { sq. }\end{array}$ & Sol'n & $\mathrm{pH}$ & $\begin{array}{c}\text { mV vs } \\
\text { SCE }\end{array}$ & Time & Average & Selectec \\
\hline DON1 & 13 & $\mathrm{AP}$ & 7.4 & -150 & $5 \mathrm{~min}$ & $2.5 \mathrm{E}+03$ & $\begin{array}{lllll}3.1 & 2.8 & 1.6 & 2.4 & 2.8 \text { (XE3 }\end{array}$ \\
\hline DON1 & & & & & $1 \mathrm{~min}$ & $2.3 \mathrm{E}+03$ & $\begin{array}{llllll}3.0 & 1.3 & 4.7 & 1.3 & 1.4(\mathrm{xE} 3 \\
\end{array}$ \\
\hline DON1 & & & & & $15 s$ & $3.5 \mathrm{E}+03$ & $\begin{array}{lllll}4.3 & 2.9 & 3.5 & 3.3(\mathrm{xE} 3\end{array}$ \\
\hline$\overline{\mathrm{DON} 1}$ & & & & -300 & $5 \min$ & $2.8 \mathrm{E}+03$ & $\begin{array}{lllll}2.9 & 3.1 & 2.5 & 2.8 & 2.5(\mathrm{xE} 3\end{array}$ \\
\hline DON1 & & & & & $1 \mathrm{~min}$ & $2.9 \mathrm{E}+03$ & $\begin{array}{lllll}2.3 & 2.8 & 3.3 & 3.2(x E 3\end{array}$ \\
\hline DON1 & & & & & $15 s$ & $4.2 \mathrm{E}+03$ & $3.94 .355 .0 \quad 5.0 \quad 3.0(\mathrm{xE} 3$ \\
\hline DON1 & & & & -450 & $5 \mathrm{~min}$ & $3.3 \mathrm{E}+03$ & $2.03 .13 .522 .4 \_5.6(\mathrm{xE} 3$ \\
\hline DON1 & & & & -750 & $5 \mathrm{~min}$ & $3.4 \mathrm{E}+03$ & $3.11 .66 .32 .8(\mathrm{xE})$ \\
\hline DON1 & & & & -1000 & $5 \mathrm{~min}$ & $9.4 \mathrm{E}+07$ & $1 \mathrm{E} 8,8.5$ 9.3_9.7(xE7 \\
\hline
\end{tabular}

Work to select an ITO substrate material focused on ITO prepared by sputtering or ebeam using ceramic targets since suppliers and the literature indicated that reactive sputtering and spray pyrolysis (typically used for FTO deposition) give less consistent results. Eight types of specimens from various sources were tested by depositing Pt nuclei at $-0.45 \mathrm{~V}$ for 5

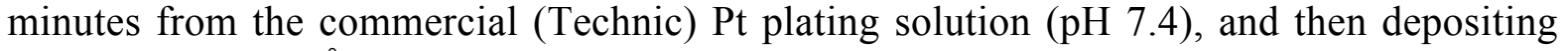
silver islands ( $500 \AA$ mirror equivalent) on the Pt nuclei from the GBL electrolyte. The data are summarized in Table 6. For all of the ITO materials, the average dot density was in the 103 to $104 / \mathrm{cm} 2$ range but only the Quantum Coatings e-beam material (QUA1) and the Gentex sputtered material (GEN1) gave an even island distribution. Both of these materials were prepared using a substrate temperature of about $300^{\circ} \mathrm{C}$. The other ITO materials exhibited much higher island densities in some areas, indicative of surface inhomogeneities or damage. Subsequent work focused on the Gentex material. 
Table 6

Platinum Nuclei Density for Various ITO Substrate Materials

\begin{tabular}{|c|c|c|c|c|c|}
\hline \multicolumn{3}{|c|}{ ITO Characteristics } & \multicolumn{2}{|r|}{ Dot Density $/ \mathrm{cm}^{2}$} & Dot Distribution Comments \\
\hline ITO & $\begin{array}{c}\text { Ohm/ } \\
\text { sq. }\end{array}$ & Preparation & Average & Selected & \\
\hline DON1 & 13 & Sputtered & $3.3 \mathrm{E}+03$ & $\begin{array}{llllll}2.0 & 3.1 & 3.5 & 2.4 & 5.6(x E 3)\end{array}$ & Uneven \\
\hline AF4 & 10 & Sputtered & $5.7 \mathrm{E}+03$ & $5.7 \quad 10.5 \quad 1.4 \quad 7.4 \_3.6(x E 3)$ & Uneven \\
\hline DAF1 & 11 & Sputtered & $7.2 \mathrm{E}+03$ & 7.6_10.2_8.8_3.8_8.0_7.4_4.6(xE3) & Uneven (high density bands) \\
\hline TFT1 & 9 & Low O2 Sputter & $5.5 E+03$ & 8.4_3.4_4.8_5.2_4.9_5.7_5.2_6.5(xE3) & Uneven (high density spots) \\
\hline TFT2 & 9 & Reg. O2 Sputter & $2.5 \mathrm{E}+03$ & 2.0_2.2_2.8_1.5_3.9_2.6(xE3) & Uneven \\
\hline ZCR1 & 17 & Ion-Assist e-Beam & $1.1 \mathrm{E}+04$ & 9.1_8.2_9.9_15.9_9.7_12.2(xE3) & Uneven \\
\hline QUA1 & 10 & e-Beam & $1.1 \mathrm{E}+03$ & $0.710 .85 \quad 0.70 \quad 0.68 \quad 2.4 \quad 1.5 \quad 1.2(x E 3)$ & Even (except small spots) \\
\hline GEN1 & 12 & Sputtered $\left(300^{\circ} \mathrm{C}\right)$ & $6.0 \mathrm{E}+03$ & $4.89 .1 \_8.61 .7(x E 3)$ & Even (except small spots) \\
\hline
\end{tabular}

In addition, preliminary tests were performed to determine the effects of pretreatments with oxygen plasma $(200 \mathrm{~W}$ for 5 minutes) and steam fogging (used for inspection to detect defects) on the density of Pt nuclei (deposited at $-0.45 \mathrm{~V}$ for 5 minutes from the $\mathrm{pH} 7.4 \mathrm{Pt}$ plating bath). The steam fogging treatment had no effect. As shown in Table 7, the oxygen plasma treatment reduced the Pt nuclei density (active ITO sites) by more than two orders of magnitude.

Table 7

Effect of Oxygen Plasma Treatment on Platinum Nuclei Density

\begin{tabular}{|l|c|c|c|r|}
\hline \multicolumn{3}{|c|}{ ITO Characteristics } & \multicolumn{2}{c|}{ Dot Density/cm ${ }^{2}$} \\
\hline ITO_ & $\begin{array}{c}\text { Ohm/ } \\
\text { sq. }\end{array}$ & Preparation & Average & Selected \\
\hline AF4 & 10 & Sputtered & $5.7 \mathrm{E}+03$ & $5.7 \_10.5$ 1.4_7.4_3.6(xE3) \\
\hline AF4 & 10 & O2 Plasma Cleaned & $1.2 \mathrm{E}+01$ & $8,8,8,23$ \\
\hline
\end{tabular}

\subsubsection{Platinum Plating Bath Selection}

Under this subtask, a plating bath providing the optimum density of Pt nuclei $\left(10^{6} / \mathrm{cm}^{2}\right)$ on ITO substrates was identified. In addition to the $\mathrm{pH} 7.4$ bath used in previous work, commercial baths (Technic) operating at $\mathrm{pH}$ 1, $\mathrm{pH} 3$ and $\mathrm{pH} 11.5$ were investigated. Table 8 summarizes the results. The $\mathrm{pH} 1$ bath visibly attacked the ITO surface (for longer plating times) and yielded very high Pt nuclei densities $\left(10^{8} / \mathrm{cm}^{2}\right.$ to $10^{9} / \mathrm{cm}^{2}$ range). The $\mathrm{pH} 3$ bath was much less aggressive toward the ITO surface but yielded nuclei densities in the same range. Best results were obtained for the $\mathrm{pH} 11.5$ bath, which yielded relatively uniform dot densities in the $10^{5} / \mathrm{cm}^{2}$ to $10 \% \mathrm{~cm}^{2}$ range, which is nearly optimum. Lines with high densities of platinum dots were observed on specimens plated from the $\mathrm{pH} 11.5$ bath, and were subsequently found to result from minor scratches caused by brushes used in machine washing of the ITO after deposition. These lines were eliminated by deleting the machine-washing step in the ITO fabrication process, which also significantly improved the consistency of the dot density. 
Table 8

Effect of Bath pH on Platinum Nuclei Density

\begin{tabular}{|c|c|c|c|c|c|c|c|c|}
\hline ITO & \multicolumn{5}{|c|}{ Pt Plating } & \multicolumn{2}{|r|}{ Dot Density $/ \mathrm{cm}^{2}$} & \multirow[t]{2}{*}{ Dot Distribution Comments } \\
\hline ITO & Sol'n & $\mathrm{pH}$ & ${ }^{\circ} \mathrm{C}$ & $\begin{array}{l}\text { mV vs } \\
\text { SCE }\end{array}$ & Time & Average & Selected & \\
\hline GEN1 & TP & 1 & 49 & +200 & $5 \mathrm{~min}$ & $5.1 \mathrm{E}+07$ & 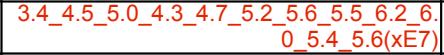 & Even overall \\
\hline GEN1 & TP & 1 & & +100 & $5 \min$ & $4.5 \mathrm{E}+08$ & $\begin{array}{r}2.7 \_2.6 \_2.8 \_2.8 \_3.7 \_3.5 \_5.6 \_4.6 \_3.9 \_3 . \\
67.58 .97 .82 .2(x \mathrm{E} 8)\end{array}$ & Even overall \\
\hline GEN1 & TP & 1 & & -100 & $5 \mathrm{~min}$ & $5.3 E+08$ & 5.6_7.6_5.8_3.9_4.6_4.0(xE8) & Even overall \\
\hline GEN1 & $\mathrm{S}$ & 3 & 71 & -100 & $5 \mathrm{~min}$ & $1.5 \mathrm{E}+08$ & $1.011 .0 \_1.9 \_1.3 \_1.7 \_1.5 \_1.8 \_1.6(x E 8)$ & Good but not perfect (TP bath better) \\
\hline GEN1 & $\mathrm{S}$ & 3 & & -100 & $2.5 \mathrm{hr}$ & $6.2 \mathrm{E}+08$ & 5.9_5.3_8.9_6.1_6.7_6.7_7.2 & Good but not perfect (TP bath better) \\
\hline GEN1 & $\mathrm{S}$ & 3 & & -300 & $5 \mathrm{~min}$ & $7.7 \mathrm{E}+08$ & $\begin{array}{r}5.7 \text { 5.8_6.6_8.5_10.5_6.9_7.5_7.0_11.0( } \\
\text { xE8) }\end{array}$ & Good but not perfect (TP bath better) \\
\hline GEN1 & $\mathrm{S}$ & 3 & & -450 & $5 \mathrm{~min}$ & & & Heavy deposit in many areas (No SEM) \\
\hline GEN1 & $\mathrm{AP}$ & 7.4 & 74 & -450 & $5 \mathrm{~min}$ & $6.0 \mathrm{E}+03$ & 4.8_9.1_8.6_1.7(xE3) & Generally even. \\
\hline GEN1 & AP & 7.4 & & -750 & $5 \mathrm{~min}$ & 1.1E+04 & 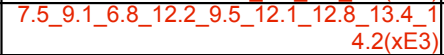 & Very dense at top. \\
\hline GEN1 & $\mathrm{AP}$ & 7.4 & & -1000 & $5 \mathrm{~min}$ & $6.5 \mathrm{E}+07$ & 2.2_1.5_15.1_4.1_9.6(xE7) & Very dense at top. Large \& small dots. \\
\hline GEN1 & A & 11.5 & 80 & -100 & $5 \mathrm{~min}$ & $4.4 \mathrm{E}+06$ & $\begin{array}{r}1.4 \_1.1 \text {-1.4_1.5_1.3_1.5_2.2_1.6_1.2_1. } \\
\text { 3_1.6_1.3_1.4_9.6(xE7) }\end{array}$ & Large and small (not included) dots \\
\hline GEN1 & A & 11.5 & & -200 & $5 \mathrm{~min}$ & $9.5 E+06$ & $\begin{array}{r}9.8 \_6.8 \text { 9.2_12.3_8.8_8.1_7.9_12.5_11.5 } \\
8.4(\mathrm{xE} 6)\end{array}$ & Even overall \\
\hline GEN1 & A & 11.5 & & -200 & $2.5 \mathrm{hr}$ & $1.2 \mathrm{E}+04$ & $\begin{array}{r}1.3 \_1.3 \text {-1.1_1.1_1.0_2.0_1.2_1.1_1.111. } \\
0 \_1.2(x \mathrm{E} 4)\end{array}$ & Very uniform. No sheet resistance change. \\
\hline GEN1 & A & 11.5 & & -450 & $5 \mathrm{~min}$ & $3.1 \mathrm{E}+05$ & 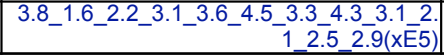 & Good (some cross hatch pattern) \\
\hline
\end{tabular}

As an alternative, a GBL electrolyte containing $0.1 \underline{\mathrm{M} \mathrm{LiCl}}$ and $0.025 \underline{\mathrm{M}}\left(\mathrm{Et}_{4} \mathrm{~N}\right)_{2} \mathrm{PtCl}_{4}$ was evaluated for Pt electrodeposition. Although the process should involve only two electrons, Pt deposition from this electrolyte did not occur even at high negative voltages (up to $-5 \mathrm{~V}$ ) that produced solvent breakdown (gas evolution). The nonaqueous approach to $\mathrm{Pt}$ deposition was abandoned since high efficiency and good results were provided by the alkaline bath.

\subsubsection{Dot Density Consistency}

Based on extensive data, plating at $-0.45 \mathrm{~V}$ from the $\mathrm{pH} 11.5$ bath provides the optimum Pt nuclei density over a wide range of plating times and ITO sputtering conditions. The glass/ITO specimens were partially submerged in the plating bath (in a beaker), which was magnetically stirred and maintained at $74^{\circ} \mathrm{C}$ (via a hotplate). The potential of the specimen was controlled relative to a saturated calomel electrode (SCE) via a potentiostat. Average dot densities were determined by visually counting dots (from SEM micrographs) at nine count areas (one millimeter apart) in a line and two count areas on either side of the line (at the line center). Each count area generally contained several hundred dots. Dot densities were generally uniform over the portion the specimen that was substantially submerged during plating but tended to be somewhat higher in the meniscus region. Typically, dot densities at the center of the specimen were representative of those over the whole surface (except the meniscus region). Note that the meniscus effect would be avoided in practice via Pt plating from a flow cell (or with total immersion).

Figure 9 shows SEM micrographs of a dot matrix electrode with 2.7 million dots $/ \mathrm{cm}^{2}$ plated from the $\mathrm{pH} 11.5$ (alkaline) plating bath at $-0.45 \mathrm{~V}$ vs. SCE for 25 minutes on an ITO substrate than had been etched in $10 \% \mathrm{HCl}$ for 5 minutes. The long plating time yielded relatively large dots $(2.4 \mu \mathrm{m}$ diameter $)$ for which the size uniformity is apparent. As discussed below, the $\mathrm{HCl}$ etch has no significant effect on the dot size or density. 


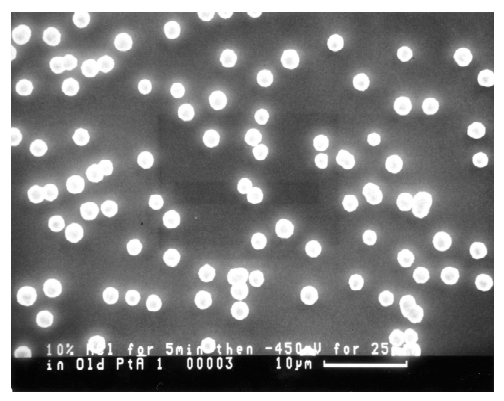

$2000 X$

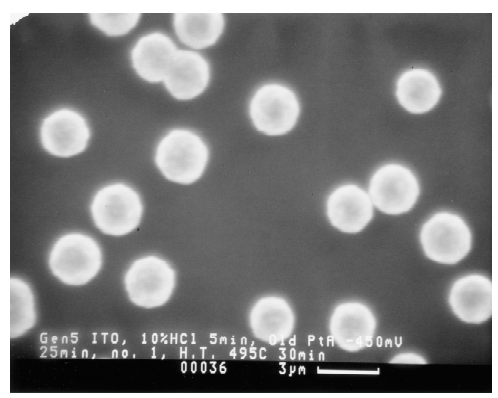

$5000 X$

Fig. 9 SEM micrograph of dot matrix counter electrode.

The data in Table 9 illustrates the consistency of the dot densities obtained for asreceived ITO material. For twenty-four specimens from two batches of Gentex ITO (Gen-3 and Gen-5) plated for times from 0.25 to 10 minutes, the measured average Pt dot density was always within the 1.0 to $2.7 \mathrm{million} / \mathrm{cm}^{2}$ range. As expected, the Pt dot diameter generally increased with plating time (from $0.5 \mu \mathrm{m}$ at $0.25 \mathrm{~s}$ to $1.9 \mu \mathrm{m}$ at 10 minutes). For 15 of these specimens plated at $-0.45 \mathrm{~V}$ for 5 minutes, the measured dot densities $(1.1-2.2$ million $\left./ \mathrm{cm}^{2}\right)$ and dot diameters $(1.3-1.4 \mu \mathrm{m})$ were constant within experimental error.

Table 10 gives the dot densities and sizes for specimens of ITO sputtered at RSC (using a ceramic target) with various oxygen pressures (0 to $1 \%)$ and various substrate temperatures $\left(190^{\circ}, 230^{\circ}\right.$ or $\left.280^{\circ} \mathrm{C}\right)$. Platinum plating was performed at $-0.45 \mathrm{~V}$ vs. SCE for 5 minutes from the $\mathrm{pH} 11.5$ plating bath $\left(74^{\circ} \mathrm{C}\right)$. Without oxygen or at low oxygen pressure, the average dot densities and sizes for these specimens sputtered with various substrate temperatures $\left(1.2-2.4 \mathrm{million} / \mathrm{cm}^{2}\right.$ and $\left.1.2-1.5 \mu \mathrm{m}\right)$ were practically the same as those obtained for as-received Gentex ITO under the same plating conditions $\left(1.1-2.2 \mathrm{million} / \mathrm{cm}^{2}\right.$ and $1.3-1.4 \mu \mathrm{m})$. This is a remarkable result demonstrating the robustness with which the alkaline bath provides the optimum dot density, practically independent of the ITO sputtering substrate temperature. An oxygen pressure of 1\% during ITO sputtering tended to decrease the dot density but the only significant decrease was for the highest substrate temperature $\left(280^{\circ} \mathrm{C}\right)$, for which the dot density was about an order of magnitude lower. This decrease is not surprising since increased oxygen pressure is known to decrease the conductivity of sputtered ITO by reducing the concentration of oxygen vacancies. It is surprising that the Pt dot density did not depend on the substrate temperature, which is known to affect the ITO crystallinity and grain size. This lack of dependence on substrate temperature implies that the active sites involved in Pt nucleation do not involve grain boundaries, which is consistent with SEM examinations of plated ITO specimens. 
Table 9

Platinum Dot Densities for As-Received ITO Plated from Alkaline Bath

\begin{tabular}{|c|c|c|c|c|c|}
\hline \multirow[t]{2}{*}{ Ref. No. } & \multirow{2}{*}{$\begin{array}{l}\text { ITO } \\
\text { Batch }\end{array}$} & \multicolumn{2}{|c|}{ Platinum Plating } & \multirow{2}{*}{$\begin{array}{l}\text { Dot Density } \\
\left(\text { million } / \mathrm{cm}^{2}\right)\end{array}$} & \multirow{2}{*}{$\begin{array}{l}\text { Dot Diameter } \\
(\mu \mathrm{m})\end{array}$} \\
\hline & & (V) & (minutes) & & \\
\hline 97 & 3 & -0.45 & 0.25 & 1.8 & 0.5 \\
\hline 109 & 3 & -0.45 & 0.5 & 2.2 & 0.7 \\
\hline 110 & 3 & -0.45 & 1 & 2.0 & 0.7 \\
\hline 111 & 3 & -0.45 & 1 & 1.8 & 0.7 \\
\hline 134 & 3 & -0.45 & 1 & 2.4 & 0.9 \\
\hline 135 & 3 & -0.45 & 1 & 2.5 & 0.9 \\
\hline 136 & 3 & -0.45 & 1 & 2.7 & 0.9 \\
\hline 113 & 3 & -0.45 & 2 & 1.9 & 0.9 \\
\hline 95 & 3 & -0.45 & 5 & 1.2 & \\
\hline 96 & 3 & -0.45 & 5 & 1.5 & \\
\hline 101 & 3 & -0.45 & 5 & 1.2 & \\
\hline 102 & 3 & -0.45 & 5 & 1.1 & \\
\hline 107 & 3 & -0.45 & 5 & 1.1 & \\
\hline 108 & 3 & -0.45 & 5 & 1.3 & 1.4 \\
\hline 142 & 3 & -0.45 & 5 & 1.8 & 1.3 \\
\hline 149 & 3 & -0.45 & 5 & 1.9 & 1.4 \\
\hline 150 & 3 & -0.45 & 5 & 1.8 & 1.3 \\
\hline 151 & 3 & -0.45 & 5 & 1.5 & 1.4 \\
\hline 156 & 3 & -0.45 & 5 & 1.3 & 1.4 \\
\hline 157 & 3 & -0.45 & 5 & 1.5 & 1.4 \\
\hline 139 & 5 & -0.45 & 5 & 1.5 & 1.3 \\
\hline 140 & 5 & -0.45 & 5 & 1.6 & 1.4 \\
\hline 141 & 5 & -0.45 & 5 & 2.2 & 1.4 \\
\hline 158 & 3 & -0.45 & 10 & 1.0 & 1.9 \\
\hline
\end{tabular}

Table 10

Effect of ITO Sputtering Variables on Density of Pt Dots Plated from Alkaline Bath

\begin{tabular}{|c|c|c|c|c|c|c|}
\hline \multirow[t]{2}{*}{ Ref. No. } & \multicolumn{2}{|c|}{ ITO Sputter Conditions } & \multicolumn{2}{|c|}{ Platinum Plating } & \multirow{2}{*}{\begin{tabular}{|l|} 
Dot Density \\
$\left(\right.$ millions $\left./ \mathrm{cm}^{2}\right)$ \\
\end{tabular}} & \multirow{2}{*}{$\begin{array}{l}\text { Dot Diameter } \\
(\mu \mathrm{m})\end{array}$} \\
\hline & $\left({ }^{\circ} \mathrm{C}\right)$ & $\left(\% \mathrm{O}_{2}\right)$ & $(\mathrm{mV})$ & (minutes) & & \\
\hline 117 & 190 & 0 & -450 & 5 & 1.3 & 1.3 \\
\hline 118 & 190 & 0.5 & -450 & 5 & 1.2 & 1.2 \\
\hline 119 & 190 & 1 & -450 & 5 & 0.91 & 1.3 \\
\hline 120 & 230 & 0 & -450 & 5 & 2.4 & 1.5 \\
\hline 121 & 237 & 1 & -450 & 5 & 2.3 & 1.7 \\
\hline 122 & 280 & 0 & -450 & 5 & 2.1 & 1.5 \\
\hline 123 & 280 & 1 & -450 & 5 & 0.092 & 0.9 \\
\hline
\end{tabular}




\subsubsection{ITO Pretreatment Effects}

Table 11 gives data showing the effects of ITO pretreatments on the Pt nuclei density and size for ITO specimens plated for 5 minutes at $-0.45 \mathrm{~V}$ from the $\mathrm{pH} 11.5$ bath. Plating on untreated ITO under these conditions always yielded dots of $1.1-2.2 \mathrm{million} / \mathrm{cm}^{2}$ density and 1.3 - $1.4 \mu \mathrm{m}$ diameter. Mild or strong chemical etching of the ITO prior to Pt plating did not significantly affect the dot density or diameter. Heat treatment of ITO in air at low temperature $\left(195^{\circ} \mathrm{C}\right)$ for 30 minutes also had no significant effect on the dot density or diameter. However, heat treatment of ITO in air at high temperature $\left(500^{\circ} \mathrm{C}\right)$ for 30 minutes reduced the dot density to $0.7 \mathrm{million} / \mathrm{cm}^{2}$ and the dot diameter to $1.1 \mu \mathrm{m}$, and increased the sheet resistance from 10 to $20 \mathrm{ohm} /$ square. These effects apparently result from formation of an insulating layer at the ITO outer surface by heat treatment at high temperature in air.

Table 11

Platinum Dot Density Substrate Effects

\begin{tabular}{|l|l|l|l|l|l|l|l|l|}
\hline Ref. No. & ITO/FTO & $\begin{array}{l}\text { ITO } \\
\text { Batch }\end{array}$ & Pretreatment & \multicolumn{2}{|l|}{ Platinum Plating } & $\begin{array}{l}\text { Post-Plating } \\
\text { Treatment }\end{array}$ & $\begin{array}{l}\text { Dot Density } \\
\left(\mathbf{m i l l i o n} / \mathbf{c m}^{2}\right)\end{array}$ & $\begin{array}{l}\text { Dot Diameter } \\
(\boldsymbol{\mu m})\end{array}$ \\
\hline 98 & ITO & 3 & None & -0.75 & 5 & None & 14 & \\
\hline Various & ITO & $3 \& 5$ & None & -0.45 & 5 & None & $1.1-2.2$ & $1.3-1.4$ \\
\hline 154 & ITO & 5 & $10 \% \mathrm{HCl} / 5 \mathrm{~min}$. & -0.45 & 5 & None & 1.5 & 1.3 \\
155 & ITO & 5 & $50 \% \mathrm{HCl} / 1 \mathrm{~min}$. & -0.45 & 5 & None & 1.6 & 1.2 \\
\hline 143 & ITO & 3 & $195^{\circ} \mathrm{C} / 30 \mathrm{~min}$. & -0.45 & 5 & None & 1.9 & 1.4 \\
144 & ITO & 3 & $500^{\circ} \mathrm{C} / 30 \mathrm{~min}$. & -0.45 & 5 & None & 0.7 & 1.1 \\
\hline 103 & ITO & 3 & None & -0.45 & 5 & $500^{\circ} \mathrm{C}$ & 1.2 & 1.5 \\
& & & & Water Jet & & 1.1 \\
\hline 152 & FTO (AFG) & 3 & Cleaned & -0.45 & 5 & None & 1.1 & 1.4 \\
153 & FTO (AFG) & 3 & Cleaned & -0.45 & 5 & None & 0.8 & 1.2 \\
\hline
\end{tabular}

Table 11 also gives preliminary data indicating that plating fluorine-doped tin oxide (FTO) from the $\mathrm{pH} 11.5$ bath at $-0.45 \mathrm{~V}$ for 5 minutes provides $\mathrm{Pt}$ dot densities and diameters comparable to those obtained on ITO specimens. The cleaned FTO specimens exhibited some local hazy spots, which may result from the film preparation method (spray pyrolysis) or the cleaning procedure. These results provide further evidence for the robustness of the Pt dot plating process.

The physical robustness of Pt nuclei plated ( 5 minutes) on GEN3 material from the $\mathrm{pH} 11.5$ bath at $-0.45 \mathrm{~V}$ vs. SCE was demonstrated by subjecting as-plated and heat-treated $\left(500^{\circ} \mathrm{C}\right.$ for 5 minutes in air) specimens to a strong DI water jet (directed at a $45^{\circ}$ angle to the specimen for two minutes). The water jet had no effect on the average dot density measured for 11 locations, which remained $1.2 \mathrm{million} / \mathrm{cm}^{2}$ for the as-plated specimen and varied by less than $25 \%$ for the heat treated specimen (within the noise). The average dot size and density measured for the heat-treated specimen after the water jet treatment are included in Table 11. 


\subsubsection{Dot Matrix Electrode Testing}

Figure 10 depicts the sealess cell used for preliminary evaluations of dot matrix electrodes. The cell comprises two electrodes that include ITO (or FTO) layers on glass panes. One electrode is positioned face up with its insulating glass substrate in contact with the bottom of a slot in a copper block and is held in place by two electrically isolated metallic spring clips. This face-up electrode is electrically contacted via the metallic portion of one of the spring clips. The other electrode is held face down in electrical contact with the outer surface of the copper block (via two spring clips) so that it crosses over the slot containing the face-up electrode at a $90^{\circ}$ angle. Electrical contact is established to the face-down electrode via the copper block. A drop of electrolyte is placed between the two electrodes to form the electrochemical cell. The depth of the slot in the copper block determines the gap between the two electrodes (typically $250 \mu \mathrm{m}$ ). The bottom face-up electrode typically comprises a thick continuous layer of silver that behaves reversibly in REM electrolytes so as to provide a potential reference for evaluations of the top "test" electrode. The sealess cell must be operated inside an inert atmosphere dry box but enables test electrodes to be readily removed for microscopic examination. In addition, electrochemical evaluations can be made of different spots of the same specimen. The copper block is sufficiently massive to provide a constant temperature when heated on a hot plate.
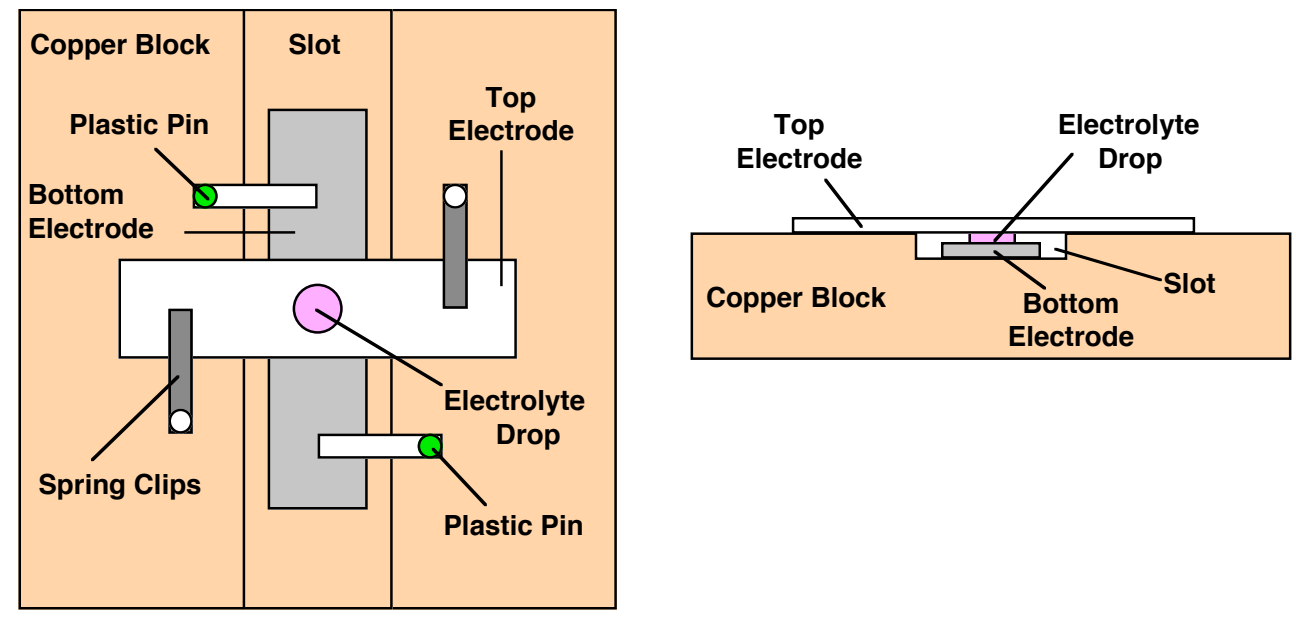

Fig. 10 Schematic of sealess cell used for dot matrix electrode evaluations.

The amount of free silver metal in REM cells is determined from the charge required to transfer all of the silver from one electrode to the other electrode. A difference in this charge from one time to another provides a measure of the amount of free silver lost by dissolution in the electrolyte via reaction with oxygen or contaminants. Under some conditions, free silver may also be lost via irreversible electrodeposition on the ITO surface and/or formation of particulates that become electrically disconnected from the electrode. 


\subsubsection{Rapid Silver Loss}

An ITO electrode (Gen-1 material) plated with Pt dots from the alkaline bath $(\mathrm{pH}$ 11.5 ) at $-450 \mathrm{mV}$ for 5 minutes and with $500 \AA$ equivalent of $\mathrm{Ag}$ was evaluated as a counter electrode in the in the sealess cell. The ITO substrate (Gen-1 material) had been machine washed so that the island density was relatively low $\left(3 \times 10^{5} / \mathrm{cm}^{2}\right)$, and the diameters of the $\mathrm{Pt}$ nuclei and the Pt/Ag islands were relatively large (4 $\mu \mathrm{m}$ and $6 \mu \mathrm{m}$, respectively). The total cross-sectional area of the dots was about $8 \%$ of the electrode area. Assuming that $75 \%$ of the dot surface was accessible for Ag deposition, the electrode should have had $25 \%$ of the current carrying capability of the mirror electrode. The electrolyte had the standard composition (1.5 $\underline{\mathrm{M}} \mathrm{AgI}$ and $2.0 \underline{\mathrm{M}} \mathrm{LiBr})$ and was prepared with unpurified Selectipur GBL solvent.

Figure 11 shows the mirror plating current (negative) and mirror erasure current (positive) for this electrode. Reproducible cathodic and anodic currents of about $1.0 \mathrm{~mA} / \mathrm{cm}^{2}$ (equivalent to $4 \mathrm{~mA} / \mathrm{cm}^{2}$ on the islands) were obtained for the first 3 plate-erase cycles or so (involving transfer of $200 \AA$ of $\mathrm{Ag}$ ) but the overall currents decreased significantly on subsequent cycles. The decrease in mirror plating current after the $3^{\text {rd }}$ cycle resulted from an increasingly rapid decrease in current later in the plating cycle (initial mirror plating current actually increased slightly on each cycle). The mirror erasure current always exhibited a large initial spike (much larger than normally observed for REM devices). At the onset of mirror electrode plating, the current sometimes exhibited an initial anodic peak, indicating formation of a species oxidizable at the mirror electrode during plating (e.g., active metallic silver or $\operatorname{Ag}(0)$ compound), or reducible at the anode during erasure (e.g., halogen). This anodic peak may also be due to concentration polarization effects. When the current was limited to $0.1 \mathrm{~mA} / \mathrm{cm}^{2}$ on the mirror electrode $\left(0.4 \mathrm{~mA} / \mathrm{cm}^{2}\right.$ on the dots $)$, the percentage decrease in current on each cycle was surprisingly much larger than for higher currents, indicating that simple concentration polarization cannot explain the results. This conclusion was also supported by the fact that the current recovery after a one-hour pause between mirror plating and erasure was small. On the other hand, 15-minute pauses between the plating and erasure portions of each cycle significantly slowed the current decay. These effects were attributed to a contaminant that presumably caused a blocking film to form on the electrode but was present at low concentration so that film formation occurred more slowly at higher current densities.

The assumption that an electrolyte contaminant caused the current at a dot matrix electrode to decrease after a few cycles in the sealess cell was tested via sealess cell evaluations involving a mirror electrode coupled with either a grid counter electrode or another mirror electrode. Similar effects were produced for both mirror and grid counter electrodes, albeit at different current densities and different numbers of cycles, as expected. Results for the grid electrode were very similar to those for the dot matrix electrode. For the unpurified electrolyte, rapidly decaying currents were also observed for dot matrix electrodes having the optimum dot density $\left(1-3 \mathrm{million} / \mathrm{cm}^{2}\right)$ and no surface damage, prepared with ITO for which machine washing had been omitted (Gen-3). 


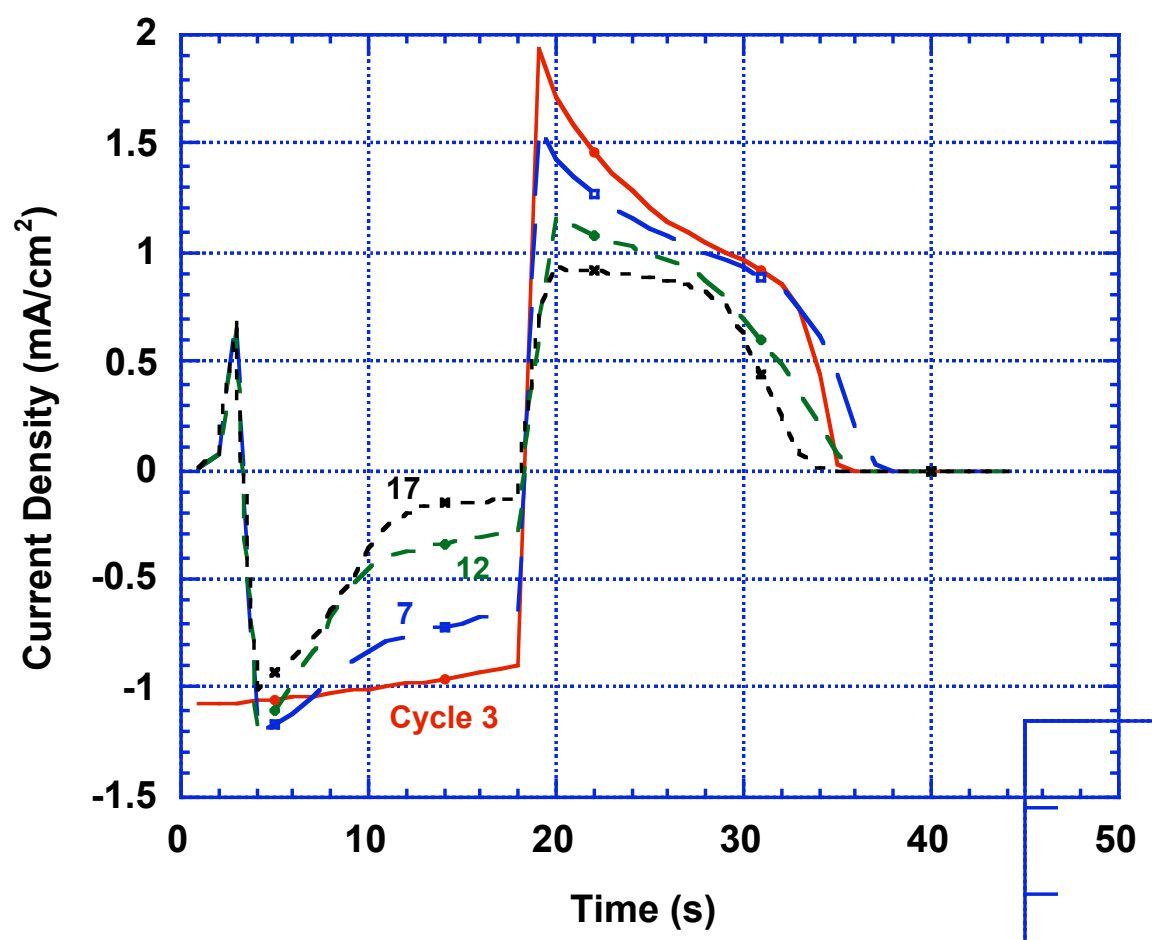

Fig. 11 Mirror plating and erasure currents for $200 \AA$ silver transfers (initially) at a dot matrix electrode with 0.3 million $\mathrm{Pt} / \mathrm{Ag}$ islands $/ \mathrm{cm}^{2}(6 \mu \mathrm{m}$ diameter) in unpurified GBL electrolyte in the sealess cell.

Contaminants were shown to be primarily responsible for the rapidly decreasing currents observed for dot matrix electrodes after a few cycles in unpurified electrolyte. Relatively stable currents were obtained for dot matrix electrodes having 2 - 3 million Pt dots $/ \mathrm{cm}^{2}$ with $1000 \AA$ silver (mirror equivalent) cycled in purified electrolyte (distilled GBL) in the sealess cell with $100 \AA$ and $200 \AA \mathrm{Ag}$ transfers at $2-5 \mathrm{~mA} / \mathrm{cm}^{2}$ (on dots assuming 0.75 active surface area). Some benefit may also have been provided by use of a series resistor (500 ohms) to suppress current spikes.

Figure 12 shows the mirror plating and erasure currents for a dot matrix electrode with 2 million Pt dots $/ \mathrm{cm}^{2}$ (1.4 $\mu \mathrm{m}$ diameter) cycled in purified electrolyte (distilled GBL) in the sealess cell (454-ohm series resistor) with $200 \AA$ silver transfers. The currents in this case are relatively high $\left(1 \mathrm{~mA} / \mathrm{cm}^{2}\right.$ on the mirror electrode and about $4 \mathrm{~mA} / \mathrm{cm}^{2}$ on the dot matrix electrodes) but are much more stable than those observed for the unpurified electrolyte. Nonetheless, currents were still found to decay slowly (over hundreds of cycles) during continuous cycling, and to be accompanied by a loss of silver. These effects may be at least partially attributable reduced cell area associated with shrinkage of the electrolyte drop due to solvent evaporation, which was visually evident. An electrolyte having an enhanced halide/silver content $(0.75 \underline{\mathrm{M} \mathrm{AgI}}+0.75 \underline{\mathrm{M}} \mathrm{LiI}+2.0 \underline{\mathrm{M} \mathrm{LiBr}})$ designed to enhance silver dissolution and inhibit electrode film formation did not prevent the slow current decay. 


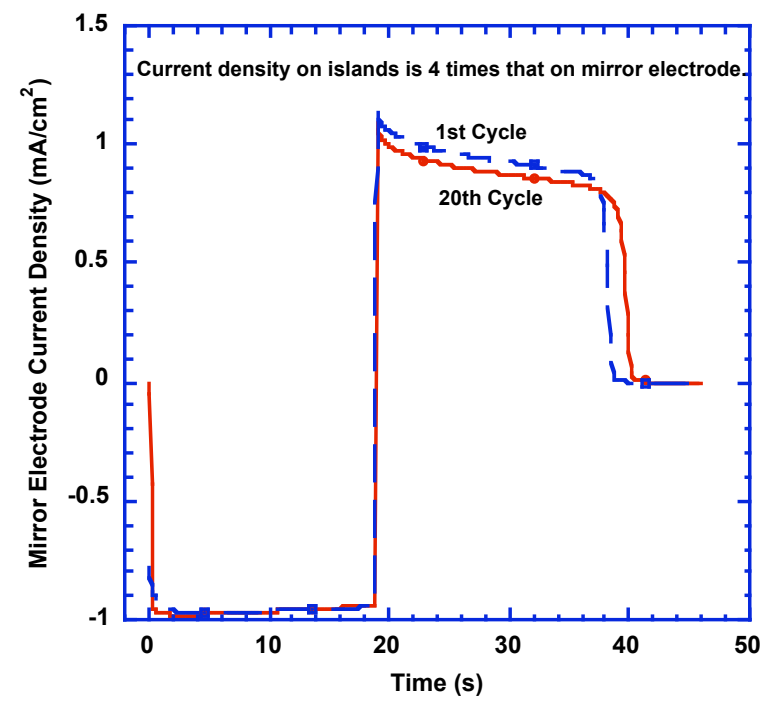

Fig. 12 Mirror plating and erasure currents for $200 \AA$ silver transfers at a dot matrix electrode with 2 million $\mathrm{Pt}$ dots $/ \mathrm{cm}^{2}$ (1.4 $\mu \mathrm{m}$ diameter) in purified GBL electrolyte in the sealess cell.

\subsubsection{Slow Silver Loss}

Cycle tests with dual-mirror cells showed that slow silver loss resulted partly from reaction with contaminants present in the Aldrich GBL solvent, and partly from inefficient $\mathrm{Ag}$ plating/erasure due to poor quality of some ITO/Pt electrodes provided by an outside supplier. These two modes of silver loss can be readily distinguished. Silver loss due to an electrolyte contaminant tends to disappear after the contaminant is consumed, whereas inefficient plating/erasure causes continuing silver loss with cell cycling. Cycle testing ( $400 \AA$ $\mathrm{Ag}$ transfers at $3.5 \mathrm{~mA} / \mathrm{cm}^{2}$ ) was performed under nitrogen for nine 5-cm dual-mirror cells (EC286 seals) made using one batch of ITO from Supplier A platinized at RSC and two batches of ITO (B-6 and B-7) produced and platinized by Supplier B, and as-received and vacuum-distilled Aldrich GBL (once or three times inside a nitrogen atmosphere) and vacuum-distilled EM Sciences GBL. To minimize the possibility of contamination from epoxy byproducts, the seal epoxy was cured overnight before filling the cells, and the cells were evacuated just prior to filling to remove any volatile species released during seal curing. Three cells employing ITO platinized at RSC and three types of Aldrich GBL (as-received, once distilled and triple distilled) all exhibited rapid silver loss of $200-600 \AA$ within the first 1000 cycles but thereafter (up to $11 \mathrm{~K}$ cycles) a very low silver loss rate (about $4 \AA / \mathrm{Kcycle}$ ). Four cells employing B-7 ITO platinized at Supplier B and different types of Aldrich GBL all exhibited rapid silver loss of $100-500 \AA$ within the first 1000 cycles and thereafter (up to $4 \mathrm{~K}-16 \mathrm{~K}$ cycles) lower but still high rates of silver loss $(20-30 \AA / \mathrm{Kcycle})$. One cell employing B-7 ITO platinized at Supplier B and once-distilled EM Sciences GBL exhibited 
lower silver loss rates than the other B-7 cells, both initially ( $75 \AA$ within the first 1000 cycles) and up to $9 \mathrm{~K}$ cycles $(11 \AA /$ Kcycle $)$. One cell employing B-6 ITO platinized at

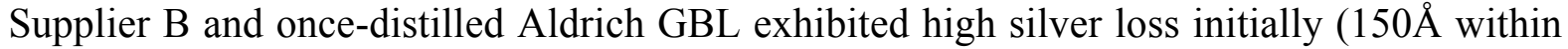
the first 1000 cycles) and very high silver loss $(70 \AA / \mathrm{Kcycle})$ up to $16 \mathrm{~K}$ cycles. These data, which are supported by numerous earlier results, show that large contributors to silver loss during cycling of REM cells are an impurity in Aldrich GBL (and to a lesser extent EM Sciences GBL) that is not removed by distillation, and charge inefficiency for mirror electrodes platinized at Supplier B. The data also show that the quality of the platinized B-6 material is much poorer than that of the B-7 material.

These results also demonstrate that a low silver loss rate $(4 \AA / \mathrm{kcycle})$ is attainable via removal of GBL contaminants and use of high-quality platinized ITO mirror electrodes. Contaminants in Aldrich GBL that contribute to silver loss are not removed by distillation but can be removed by reaction with silver metal, which occurs more rapidly during cell cycling. This issue could be addressed by including excess silver in REM cells to compensate for the silver loss due to reaction with contaminants. Nonetheless, it is desirable to avoid contaminants in the cell so as to preclude the possibility of detrimental long-term effects. Contaminants from the solvent were ultimately minimized by using GBL from EM Sciences. For cells employing this relatively pure solvent, initial silver loss was greatly reduced but not eliminated.

Slow silver loss was demonstrated for a dot matrix electrode $\left(1.2\right.$ million dots $\left./ \mathrm{cm}^{2}\right)$ plated on untreated ITO and cycled with $200 \AA$ silver transfers in a sealess cell with electrolyte prepared using distilled EM Sciences GBL and high-purity salts. The electrolyte was stirred over Ag foil for more than 15 hours to remove oxidizing impurities that could cause chemical dissolution of Ag deposits. Deposition in the sealess cell of the mirror equivalent of $900 \AA$ of silver at $2 \mathrm{~mA} / \mathrm{cm}^{2}$ (on dots assuming $75 \%$ available area) increased the average dot diameter from $1.5 \mu \mathrm{m}$ to about $2.5 \mu \mathrm{m}$. The cell was cycled with a 454-ohm series resistor at $2 \mathrm{~mA} / \mathrm{cm}^{2}$ for 200 cycles, and slow current decay was observed after about 50 cycles. SEM examination of the dot matrix electrode showed that the morphology of the silver on the dots was apparently unchanged but the average dot diameter had decreased significantly, from 2.5 to $1.7 \mu \mathrm{m}$.

Charge efficiency measurements for a dual-mirror cell (D-105) during 100 cycles ( $200 \AA \mathrm{Ag}$ transfers of a total of $1900 \AA$ ) indicated that the low current density on the mirror electrode was not responsible for slow silver loss in REM cells with dot matrix counter electrodes. Values measured at 20 cycle intervals ranged from 0.04 to $0.25 \%$ at $0.1 \mathrm{~mA} / \mathrm{cm}^{2}$, 0.13 to $0.47 \%$ at $0.5 \mathrm{~mA} / \mathrm{cm}^{2}$ and 1.08 to $2.25 \%$ at $2 \mathrm{~mA} / \mathrm{cm}^{2}$, and always corresponded to excess erasure charge. These values are within the noise and indicate practically $100 \%$ charge efficiency at all current densities. Since even a small charge inefficiency per cycle could have a large cumulative effect on silver loss, however, these charge efficiency data are indicative but not conclusive.

As indicated in Table 12, cycle tests involving complete silver transfers for a dot matrix electrode with 1.8 million dots $/ \mathrm{cm}^{2}$ (1.3 $\mu \mathrm{m}$ diameter) in a sealess cell showed that silver loss increases dramatically when more silver is transferred. Silver losses and charge 
inefficiencies were small for relatively small $\mathrm{Ag}$ transfers $(138,196$ and $244 \AA$ mirror thickness) but large for the large Ag transfers (476 and $465 \AA$ ) even though the plating voltages for the latter were low. These data suggest that concentration polarization plays a significant role in silver loss for larger silver transfers since such low voltages do not give appreciable Ag deposition currents on bare ITO surfaces. For the dot density and diameter used here $\left(1.8 \mathrm{million} / \mathrm{cm}^{2}\right.$ and $\left.1.3 \mu \mathrm{m}\right)$, a $500 \AA$ mirror electrode deposit corresponds to a deposit thickness of about $4000 \AA$ on the dots.

Table 12

Dot Matrix Electrode Silver Losses for Various Silver Transfer Thicknesses

$\begin{array}{llllll}\begin{array}{l}\text { Ag Transfer } \\ (\AA)\end{array} & \begin{array}{l}\text { Dot Voltages } \\ (\mathrm{mV})\end{array} & \begin{array}{l}\text { Cycles } \\ (\#)\end{array} & \begin{array}{l}\text { Dot Current } \\ \left(\mathrm{mA} / \mathrm{cm}^{2}\right)\end{array} & \begin{array}{l}\begin{array}{l}\text { Ag Loss } \\ (\AA)\end{array} \\ 138\end{array} \quad \begin{array}{l}\text { Charge Inefficiency } \\ (\%)\end{array} \\ 196 & -40 /+40 & 100 & 1.5 & 0 & 0.3 \longrightarrow 0.04 \\ 244 & -60 /+60 & 100 & 3 & 20 & 0.9 \longrightarrow 0.5 \\ 476 & -80 /+65 & 100 & 4 & 13 & 0.9 \longrightarrow 1.4 \\ 465 & -50 /+35 & 60 & 2 & 300 & 2.2-3.5 \\ & -40 /+40 & 70 & 1.5 & 288 & 3.2 \longrightarrow 1.3\end{array}$

Silver loss measurements for a dual-mirror cell during cycling with total transfer of relatively thick silver $(1900 \AA)$ indicated that concentration polarization associated with the thicker silver deposits on dot matrix electrodes contributes to silver loss only for large silver transfers at relatively high current density. Measured total silver values were: $1902 \AA$ initially; $1941 \AA$ after 400 cycles at $3.5 \mathrm{~mA} / \mathrm{cm}^{2}$ with $400 \AA \mathrm{Ag}$ transfers; $1923 \AA$ after 750 cycles at $3.5 \mathrm{~mA} / \mathrm{cm}^{2}$ with $800 \AA$ silver transfers; and $1922 \AA$ after 160 cycles at $2 \mathrm{~mA} / \mathrm{cm}^{2}$ with total silver transfers $(1920 \AA)$. These variations are within the noise, indicating no silver loss. However, 700 total silver transfers at $3.5 \mathrm{~mA} / \mathrm{cm}^{2}$ reduced the measured $\mathrm{Ag}$ from $1928 \AA \AA$ to $1752 \AA$ (by $9.1 \%$ ).

Other REM cells with dot matrix electrodes also exhibited slow silver loss that decreased with cell cycling, indicating the involvement of an impurity. One cell had a dot matrix electrode $\left(1.5 \mathrm{million} / \mathrm{cm}^{2}\right.$ of $1.4 \mu \mathrm{m}$ diameter dots) heat-treated at $500^{\circ} \mathrm{C}$ for 30 minutes in air, and was assembled using Epotek OE188 epoxy and a gelled electrolyte made with distilled GBL solvent. After the $1921 \AA$ silver charge was transferred to the dot matrix

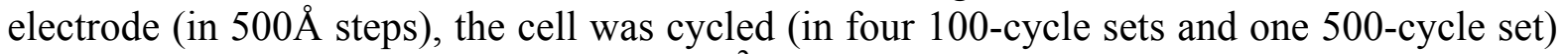
between $-110 \mathrm{mV}$ and $+90 \mathrm{mV}\left(1 \mathrm{~mA} / \mathrm{cm}^{2}\right.$ on dots assuming $75 \%$ active area). Figure 13 shows the currents during the first and third hundred cycles. Negative voltage corresponded to plating on the mirror electrode. The initial $\mathrm{Pt} / \mathrm{Ag}$ dot diameter was $3.2 \mu \mathrm{m}$, and a $375 \AA$ transfer on the mirror electrode corresponded to a thickness change of $1200 \AA$ on the matrix dots. The charge efficiency within a cycle was generally $99.8 \%$ or more for the first four sets of 100 cycles each, and was $99.7 \%$ for the last 500 cycles. Silver losses (measured for full Ag transfer with long erasure) were $310 \AA$ for the first 100 cycles, $158 \AA$ for the second 100 cycles, $115 \AA$ for the third 100 cycles, $64 \AA$ for the fourth 100 cycles (overnight erasure), and $686 \AA$ for the last 500 cycles $(137 \AA / 100$ cycles). Since concentration polarization effects 
should have been small for this dot matrix electrode under the cycling conditions used, the observed Ag loss must have resulted from impurities in the electrolyte, or extraneous deposition of silver on the ITO surface. In the latter case, irreversible extraneous silver deposition would explain the decreasing silver loss rate. Based on sealess cell tests of heattreated dot matrix electrodes (see Table 13), however, extraneous silver deposition is unlikely for this cell.
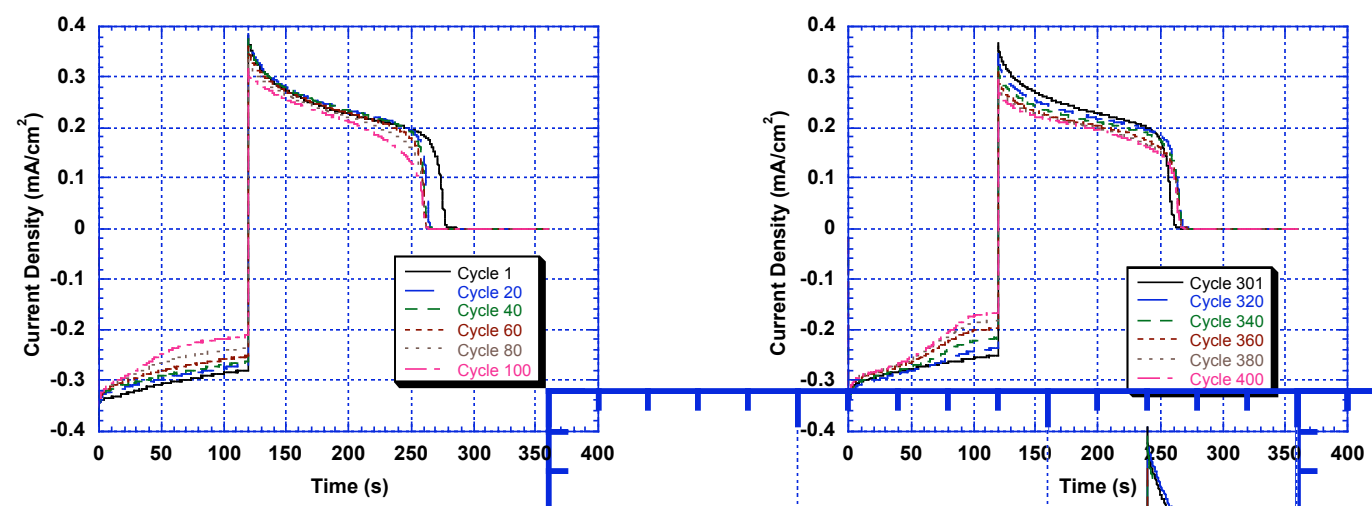

Fig. 13 Mirror plating and erasure currents for $400 \AA$ silver transfers at a dot matrix electrode with 1.5 million $\mathrm{Pt} \operatorname{dots} / \mathrm{cm}^{2}(1.4 \mu \mathrm{m}$ diameter $)$ in purified GBL electrolyte in a REM cell.

Silver loss observed during long-term cycling of cells with dot matrix electrodes was shown conclusively to be due to incompletely cured seal material (at least for EC286 epoxy), and not to coarsening of the silver layer on the Pt spheroids during cell cycling. Figure 14 shows plots of silver loss measured (at 10 or 100 cycle intervals) for several dot matrix cells as a function of the number of cycles (nominally $400 \AA$ silver transfers at $1 \mathrm{~mA} / \mathrm{cm}^{2}$ assuming $75 \%$ active dot area). Silver loss for the small (5-cm square) dot matrix cells (top three curves) plateaued at about $700 \AA$ (mirror electrode equivalent) whether the cell had $1000 \AA$ or $1700 \AA$ of silver on the mirror electrode initially. For the large cell $(10-\mathrm{cm}$ square) with the same seal, silver loss plateaued at a lower value (about $550 \AA$ ), apparently due to less contamination because of the larger electrolyte volume to seal area ratio for the larger cell. For the small cell with the EC286 seal prepared with an improved mixing and curing procedure, silver loss plateaued at even a lower value ( $300 \AA)$. Ultimately, all of these cells (and others) were cycled for more than 20,000 cycles (33,000 cycles for the large cell) with no significant increase in the silver loss rate. These results are consistent with those for dualmirror cells with improved EC286 seals, for which silver loss quickly plateaued at low values. 


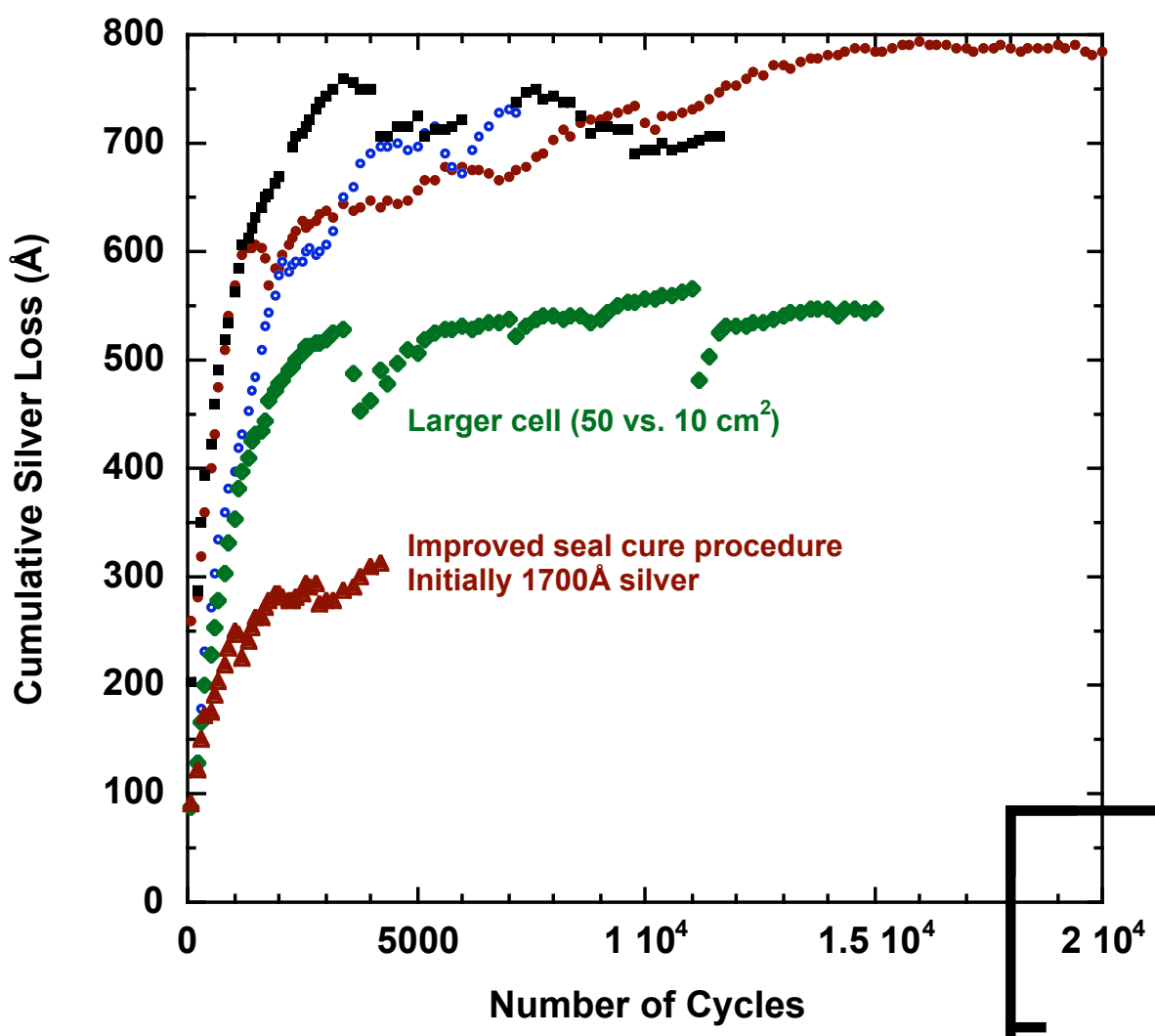

Fig. 14 Total silver loss measured for various dot matrix cells vs. number of cycles.

Cycle tests for dot matrix cells indicate no correlation with dot density (1.2 - 3.4 million/ $\left.\mathrm{cm}^{2}\right)$, Pt dot diameter $(1.8-3.3 \mu \mathrm{m})$, total dot cross-sectional area $(8-11 \%)$, dot matrix electrode heat treatment $\left(495^{\circ} \mathrm{C} / 30\right.$ minutes), switching voltage $(-120 /+90$ or $-80 /+50$ $\mathrm{mV}$ ), cycles between measurements (10 - 200), mirror electrode ITO/Pt (two suppliers), or remaining silver $(200-1400 \AA)$.

Results for three dual-mirror cells (Gen-11 and AF-10 electrodes) assembled at Gentex and filled at RSC substantiated the conclusion that impurities from the EC286 seal are responsible for silver loss in cells with dot matrix electrodes. Note that dual-mirror cells with EC286 seals also exhibit rapid silver loss for the first several thousand cycles. During cycling under the normal conditions $\left(3.5 \mathrm{~mA} / \mathrm{cm}^{2}\right.$ with $400 \AA \mathrm{Ag}$ transfers $)$, all three of these cells exhibited negligible initial silver loss. The two cells with Gen-11 electrodes exhibited no measurable silver loss up to $13 \mathrm{~K}$ cycles. Silver loss for the one cell with AF-10 electrodes was negligible up to $8 \mathrm{~K}$ cycles but increased to $560 \AA$ between $9 \mathrm{~K}$ and $22 \mathrm{~K}$ cycles. The 
increase in silver loss for the latter cell presumably resulted from a flaw in the electrodes or the cell fabrication procedure.

Some experiments were directed toward determining whether smaller platinum spheroids can be used for dot matrix electrodes to improve light transmission without causing silver loss due to transfer of thicker silver deposits on the Pt spheroids. Four cells of each type were constructed with dot matrix electrodes having comparable dot densities $(1.3-2.2$ million $/ \mathrm{cm}^{2}$ but either smaller spheroids $(0.6-0.7 \mu \mathrm{m})$ or larger spheroids $(2.3-2.5 \mu \mathrm{m})$. Half of the cells of each type had $1000 \AA$ silver and the other half had $2000 \AA$ silver. All of the cells with the larger spheroids cycled normally but the cells with the smaller spheroids could not be cycled after the initial transfer of silver from the mirror electrode to the dot matrix electrode. Apparently, the smaller spheroids lost adhesion to the ITO substrate due to stress associated with thicker silver deposits. Good cycle characteristics were observed for other cells with spheroids as small as $1.1 \mu \mathrm{m}$, which may be considered a minimum dot size. Improvement in the adhesion to the ITO substrate might enable use of submicron platinum spheroids

\subsubsection{Extraneous Silver Deposition}

Voltammetric measurements were made on bare ITO and FTO electrodes in the GBL electrolyte in the sealess cell to ascertain the conditions under which extraneous silver deposition might occur. It should be emphasized, however, that Pt nuclei on dot matrix electrodes should occupy most of the active sites at which extraneous Ag deposition would otherwise occur. The currents measured for bare ITO/FTO surfaces should, therefore, be considered a worst case with respect to extraneous Ag deposition. Nonetheless, some silver appears to be deposited on the ITO surface of dot matrix electrodes under some conditions.

Voltammetric experiments performed on bare ITO electrodes in the sealess cell showed that poorly reversible silver deposition occurs on the ITO surface at relatively low potentials, and may contribute to the slow loss of silver observed for dot matrix electrodes under some conditions. For cycling between $-250 \mathrm{mV}$ (15 seconds) and $+80 \mathrm{mV}$ (100 seconds), cathodic currents increased both with cycling and within each cycle, being about $10 \mu \mathrm{A} / \mathrm{cm}^{2}$ at the end of cycle 1 and $-80 \mu \mathrm{A} / \mathrm{cm}^{2}$ at the end of cycle 100 . The anodic currents increased more slowly with cycling $\left(20 \mu \mathrm{A} / \mathrm{cm}^{2}\right.$ at the beginning of cycle 100) and decreased slowly with time (residual current still evident after 100 seconds). Apparently, the surface of the ITO is sensitized toward Ag deposition by both voltage cycling and time at voltage, and the deposited Ag is not readily stripped from the ITO surface. For cycling between $-200 \mathrm{mV}$ (15 seconds) and $+80 \mathrm{mV}$ (100 seconds), the behavior was similar except that the currents were smaller (cathodic current $-20 \mu \mathrm{A} / \mathrm{cm}^{2}$ at the end of cycle 100). For cycling between $150 \mathrm{mV}$ ( 25 seconds) and $80 \mathrm{mV}$ (100 seconds), the cathodic current was about $1 \mu \mathrm{A} / \mathrm{cm}^{2}$ at the end of cycle 100. Note that absolute currents for Ag deposition on ITO are variable but follow the indicated trends for a given set of experiments.

Deposition of Ag on ITO was also investigated (at less negative deposition potentials) by applying a given negative voltage for 15 minutes, cycling for $10-20$ cycles between the negative voltage $(6 \mathrm{~min}$.) and a fixed positive voltage $(6 \mathrm{~min}$.), and applying the negative voltage for 15 minutes. This test procedure emphasized time (with applied voltage) as a 
factor in extraneous Ag deposition. For $-150 \mathrm{mV}$, the negative current increased from about 1 to $-23 \mu \mathrm{A} / \mathrm{cm}^{2}$ in the initial 15 minutes, was $50 \mu \mathrm{A} / \mathrm{cm}^{2}$ after 10 cycles $( \pm 150 \mathrm{mV})$, and was $54 \mu \mathrm{A} / \mathrm{cm}^{2}$ after the final 15 minutes. The anodic currents were generally smaller and decreased slowly with time. These data show that time with applied negative voltage is an important factor for Ag deposition on the ITO surface.

At the least negative voltages investigated, the rate of Ag deposition on ITO was much lower. For $-80 \mathrm{mV}$, the cathodic currents measured after the initial 15 minutes, after 10 cycles $\left( \pm 80 \mathrm{mV}\right.$ ), and after the final 15 minutes never exceeded $1.5 \mu \mathrm{A} / \mathrm{cm}^{2}$ (anodic currents were generally smaller and decreased with time). For $-50 \mathrm{mV}$ negative potential, the cathodic current remained steady at $-0.1 \mu \mathrm{A} / \mathrm{cm}^{2}$ for 15 minutes, increased to $-0.3 \mu \mathrm{A} / \mathrm{cm}^{2}$ during cycling, and increased to $0.6 \mu \mathrm{A} / \mathrm{cm}^{2}$ during the final 15 minutes (at $-50 \mathrm{mV}$ ), and the anodic currents were generally smaller and decreased slowly with time. These results show that poorly reversible Ag deposition occurs on bare ITO even at $-50 \mathrm{mV}$, albeit at sub-microamp currents. It might be possible to effectively suppress Ag loss by closely controlling the cathode voltage and allowing sufficient time for erasure of minor extraneous silver deposits, but a more robust dot matrix electrode is highly desirable.

Oxygen plasma treatment was investigated for suppressing Ag deposition on the ITO surface. Specimens plasma treated ( 5 minutes at 0.55 torr oxygen) at $400 \mathrm{~W}$ and $200 \mathrm{~W}$ were voltage cycled in a sealess cell between $-120 \mathrm{mV}$ (30 seconds) and $80 \mathrm{mV}$ (100 seconds) in the standard GBL electrolyte. Currents on the first cycle for the plasma treated specimens were small but rapidly grew with cycling and time, reaching about 10 and $30 \mu \mathrm{A} / \mathrm{cm} 2$ at the end of the $10^{\text {th }}$ cycle for the 400 and $200 \mathrm{~W}$ specimens, respectively. The effect of oxygen plasma treatment seems to be short-lived, and may ultimately be detrimental since the comparable current was less than $5 \mu \mathrm{A} / \mathrm{cm}^{2}$ for an untreated ITO specimen. However, it should be kept in mind that the effects of oxygen plasma on sites at which silver deposits may be different than on sites at which platinum deposits.

Promising results were obtained for an approach of suppressing extraneous Ag deposition on ITO by applying a submicron layer of insulating oxide $\left(\mathrm{SiO}_{2}\right.$ or $\left.\mathrm{SnO}_{2}\right)$ to a dot matrix electrode with micron-sized $\mathrm{Pt}$ dots by sol-gel processing. In this case, the electrode would be dip coated with a sol-gel solution containing dissolved metal ions and organic oxygen-containing species, and then heat treated in air $\left(200-300^{\circ} \mathrm{C}\right)$ to produce the metal oxide. A $0.2 \mu \mathrm{m}$-thick silica sol-gel coating $\left(\mathrm{SiO}_{2}\right)$ on ITO suppressed the Ag deposition current (measured after 15 minutes) to $-1.3 \mu \mathrm{A} / \mathrm{cm}^{2}$ at $-100 \mathrm{mV},-3.6 \mu \mathrm{A} / \mathrm{cm}^{2}$ at $-150 \mathrm{mV}$ and $-28 \mu \mathrm{A} / \mathrm{cm}^{2}$ at $-200 \mathrm{mV}$. For comparison, uncoated ITO exhibited a Ag deposition current of $23 \mu \mathrm{A} / \mathrm{cm}^{2}$ at $-150 \mathrm{mV}$. A $0.5 \mu \mathrm{m}$-thick silica sol-gel coating (prepared using a different precursor) exhibited no measurable Ag deposition current after 15 minutes at $-100 \mathrm{mV}$, and currents of $<-1 \mu \mathrm{A} / \mathrm{cm}^{2}$ at $-150 \mathrm{mV},-1 \mu \mathrm{A} / \mathrm{cm} 2$ at $-200 \mathrm{mV}$ and $-2 \mu \mathrm{A} / \mathrm{cm} 2$ at $-250 \mathrm{mV}$. Solgel silica coatings could be applied to dot matrix electrodes as a means of preventing extraneous Ag deposition. A sol-gel solution developed at RSC readily wets ITO and hopefully will not wet platinum so that the insulating sol-gel oxide will not deposit on the Pt dots. In any case, the oxide on the Pt dots should be relatively thin (because of the small radius of curvature) so that it can be removed by selective etching. Alternatively, the 
insulating oxide layer could be deposited by sputtering and removed from the Pt dots by backsputtering.

Dot matrix electrodes with a sol-gel $\mathrm{SiO}_{2}$ coating between the $\mathrm{Pt}$ dots were successfully fabricated and shown to exhibit good current carrying capability in the GBL electrolyte (sealess cell). Such $\mathrm{SiO}_{2}$ coatings were previously shown to effectively suppress silver electrodeposition on the ITO surface from the GBL electrolyte. A thin layer of sol-gel $\mathrm{SiO}_{2}(\sim 500 \AA$ thick$)$ did not cover over micron-sized Pt dots, which continued to function as dot matrix electrodes after the sol-gel deposition. Platinum dots covered by a thicker sol-gel $\mathrm{SiO}_{2}$ layer $(\sim 1000 \AA$ thick) were exposed by etching in dilute HF solution (which reduced the overall sol-gel coating thickness to about $500 \AA$ ). Optical microscopy showed that all of the $\mathrm{Pt}$ dots for such sol-gel coated electrodes were uniformly active, yielding Pt/Ag islands of uniform diameter.

\subsubsection{Silver Loss Prevention}

Silver loss due to concentration polarization effects at dot matrix electrodes can be suppressed by controlling the primary parameters of current density and thickness of $\mathrm{Ag}$ transferred (for a given mirror switching thickness) via the secondary parameters of Pt dot diameter and density. Of course, light blocking by the dot matrix is a prime consideration. Figure 15 shows plots of the fraction of light blocked for Pt dots with the mirror equivalent of $1000 \AA$ of stored silver and the dot silver thickness involved in a $500 \AA$ transfer of mirror silver as functions of the Pt dot radius for various dot densities. These plots were used to determine the range of Pt dot sizes for which light blocking is acceptable (10-14\%) and the thickness of the silver transferred at the dots was limited to $2000 \AA$. For $1 \times 10^{6} / \mathrm{cm}^{2}$ dot density, the Pt dot radius needs to be $>1.5 \mu \mathrm{m}$ for $2000 \AA \mathrm{Ag}$ transfers, and $<1.4 \mu \mathrm{m}$ for $10 \%$ light blocking, $<1.65 \mu \mathrm{m}$ for $12 \%$ light blocking, and $<1.85 \mu \mathrm{m}$ for $14 \%$ light blocking (diameter range $3.0-3.7 \mu \mathrm{m}$ ). For $2 \times 10^{6} / \mathrm{cm}^{2}$ dot density, the Pt dot radius needs to be $>1.0$ $\mu \mathrm{m}$ for $2000 \AA \mathrm{Ag}$ transfers, and $<0.8 \mu \mathrm{m}$ for $10 \%$ light blocking, $<1.0 \mu \mathrm{m}$ for $12 \%$ light blocking, and $<1.2 \mu \mathrm{m}$ for $14 \%$ light blocking (diameter range $2.0-2.5 \mu \mathrm{m}$ ). These calculations show that $2-4 \mu \mathrm{m}$ is the optimum range for the Pt dot diameter at the dot densities normally obtained. Note that these are worst case estimates since silver loss due to concentration polarization is greatly reduced for periodic rather than continuous cycling. Concentration polarization may be further reduced via incremental switching. 

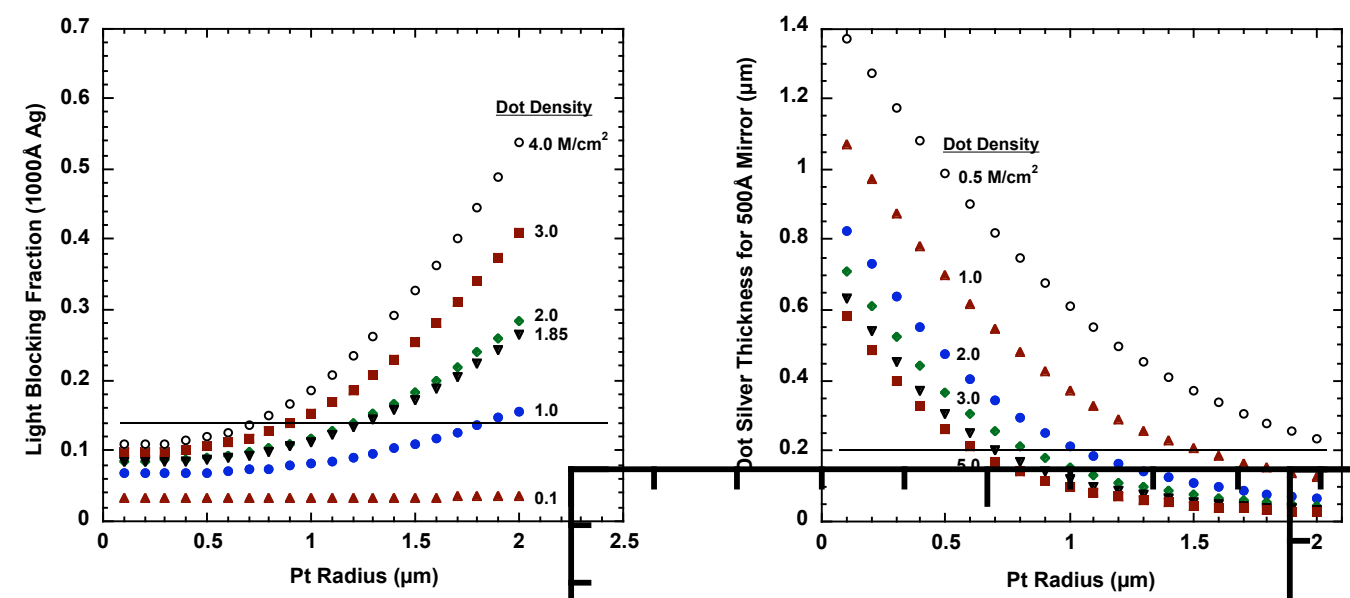

Fig. 15 Plots of the fraction of light blocked for Pt dots with the mirror equivalent of $1000 \AA$ of stored silver and the dot silver thickness involved in a $500 \AA$ transfer of mirror silver as functions of the Pt dot radius for various dot densities.

As indicated by the data in Table 13, heat treatment of a dot matrix electrode with 1.9 million dots $/ \mathrm{cm}^{2}\left(1.5 \mu \mathrm{m}\right.$ diameter) at $500^{\circ} \mathrm{C}$ for 30 minutes in air significantly suppressed loss of silver due to extraneous deposition on the bare ITO surface during potential cycling. The dot matrix electrode was cycled (in sets of 60 - 100 cycles each) with full Ag transfers

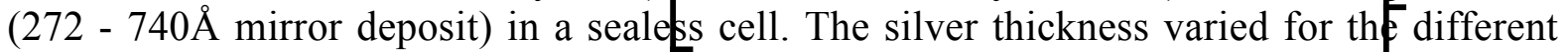
mirror electrodes used for the tests. Figure 16 shows the plating and erasure currents during 100 cycles involving about $600 \AA$ silver transfers. In most cases, a series resistor $(1 \mathrm{~K}-4 \mathrm{~K})$ was used to provide a relatively constant current density of $2 \mathrm{~mA} / \mathrm{cm}^{2}$ (for which concentration polarization is small), which also increased the switching voltages.

Table 13

Silver Losses for Heat-Treated Dot Matrix Electrode

$\begin{array}{lllllll}\begin{array}{l}\text { Mirror Ag } \\ (\AA)\end{array} & \begin{array}{l}\text { Voltages } \\ (\mathrm{mV})\end{array} & \begin{array}{l}\text { Resistor } \\ (\mathrm{Ohms})\end{array} & \begin{array}{l}\text { Current } \\ \left(\mathrm{mA} / \mathrm{cm}^{2}\right)\end{array} & \begin{array}{l}\text { Cycles } \\ (\#)\end{array} & \begin{array}{l}\text { \% Charge } \\ \text { Efficiency }\end{array} & \begin{array}{l}\text { Ag Loss } \\ (\AA)\end{array} \\ 272 & -40 /+45 & 0 & 1.1 & 80 & >99.9 & 22 \\ 639 & -100 /+100 & 1 \mathrm{~K} & 2.2 & 60 & 99.6 & 95 \\ 580 & -150 /+150 & 2 \mathrm{~K} & 2.2 & 80 & >99.9 & +41 \\ 627 & -200 /+200 & 3 \mathrm{~K} & 2.2 & 100 & 99.6 & 77 \\ 740 & -250 /+250 & 4 \mathrm{~K} & 2.2 & 80 & 99.1 & 200\end{array}$




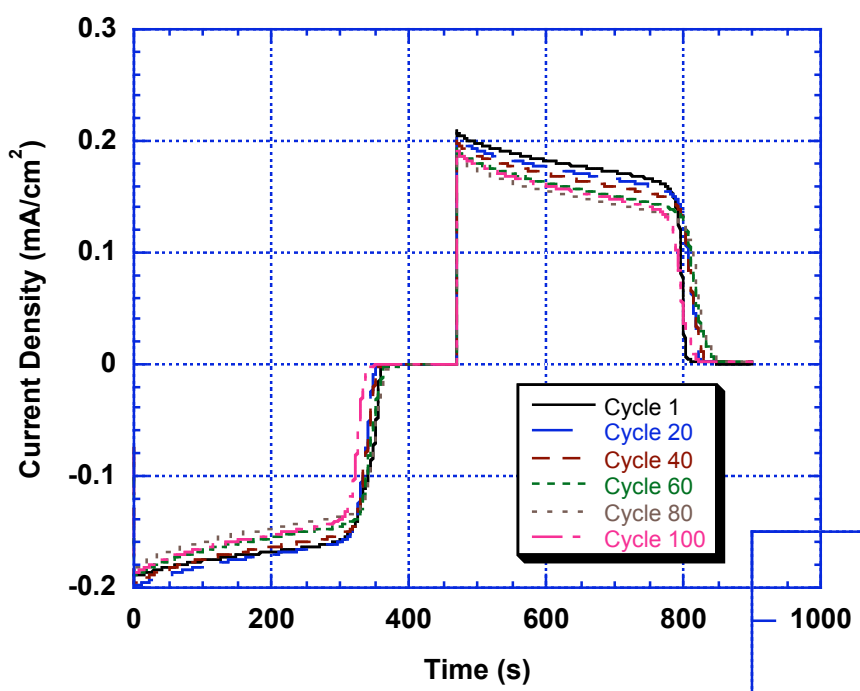

Fig. 16 Mirror plating and erasure currents during full $600 \AA$ silver transfers for a heat-treated dot matrix electrode with 1.9 million $\mathrm{Pt}$ dots $/ \mathrm{cm}^{2}(1.5$ $\mu \mathrm{m}$ diameter) in purified GBL electrolyte in the sealess cell.

Measured silver loss tended to increase with cycling but this may have resulted from a reduction in cell area due to electrolyte evaporation, which was visually evident in some cases. Nonetheless, except for the $740 \AA$ transfer (at a relatively high voltage of $250 \mathrm{mV}$ ), silver loss was at the noise level $(100 \AA)$ and current efficiency (which may be a better measure of lack of Ag loss in this case) was high ( $>99.5 \%)$. Since the full negative voltage was applied to the dot matrix electrode on each cycle (when the Ag was fully erased from the mirror electrode), the heat treatment was apparently effective at suppressing extraneous Ag deposition on the bare ITO surface up to $-200 \mathrm{mV}$. However, the Ag deposition current measured in the sealess cell after 15 minutes at $-150 \mathrm{mV}$ was about the same $\left(25 \mu \mathrm{A} / \mathrm{cm}^{2}\right)$ for the heat-treated and as-received bare ITO (no Pt dots). These results indicate that Ag deposition occurs at specific sites that are not active for Pt deposition but are deactivated by heat treatment.

\subsubsection{Conducting Polymer Counter Electrode}

An alternative approach to providing uniform switching by using a conducting polymer (polyaniline) film for the counter electrode in transmissive REM devices was demonstrated. In this case, silver loss is not an issue since the counter electrode reaction is oxidation/reduction of the conducting polymer rather than reversible silver electrodeposition, and excess silver can be stored along the perimeter of the mirror electrode. In addition, uniformity of the fully switched mirror is ensured by the limited capacity of the polymer film, which assumes a green-blue color in the oxidized state that obscures the back of the mirror. Polyaniline was chosen as the conducting polymer material since it is transparent in the reduced state (corresponding to erasure of the REM mirror by silver oxidation) but becomes green and then blue when oxidized (corresponding to formation of the REM mirror by silver reduction). Other conducting polymers tend to be colored in the oxidized state.

Figure 17 shows a REM device with a polyaniline film counter electrode and an ionic liquid electrolyte in the transmissive state and the mirror state (backside and frontside). As a

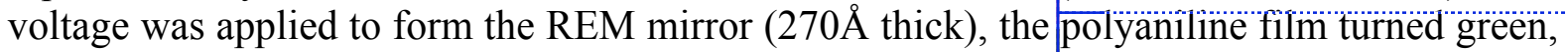


masking the backside of mirror electrode. The polymer film, which had an average molecular weight of $65 \mathrm{~K}$, was prepared by spin coating from a solution of PANI emeraldine base onto platinized ITO $(15 \AA \mathrm{Pt})$ with an adhesion layer of ceria (applied by spin coating from a colloidal ceria solution and heating at $80^{\circ} \mathrm{C}$ overnight). Similar films made with polyaniline of lower molecular weight (5000) exhibited significantly less charge capacity (based on REM mirror density). Test cells employed a $15 \AA \mathrm{Pt} / \mathrm{ITO}$ mirror electrode and had a $3 \times 3 \mathrm{~cm}$ window and a $0.2 \mathrm{~mm}$ gap (defined by platers' tape). The electrolyte was an ionic liquid containing $0.9: 0.1: 0.75$ mole ratios, respectively, of ethylmethylimidazolium chloride (EMIC), butylmethylpyrrolidinium chloride (BMPC) and silver chloride. Nearly-opaque specular mirrors were formed at $-0.8 \mathrm{~V}$ in about one minute and were erased in about the same time by short circuiting the cell. A colorless polymer film, rather than pale yellow, was attained via complete reduction of the polymer film. The polymer film test cells were assembled very crudely (by squishing the ionic liquid between the electrodes, wiping off the excess, and applying epoxy) and could only be cycled a few thousand times.

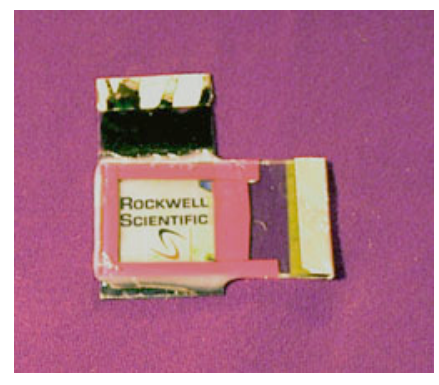

Transmissive

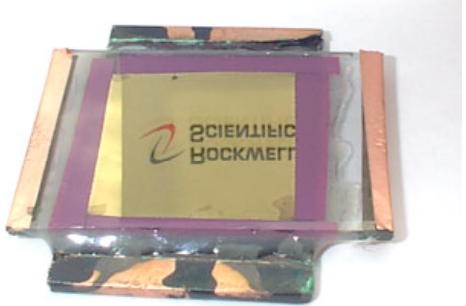

Reflective (Front)

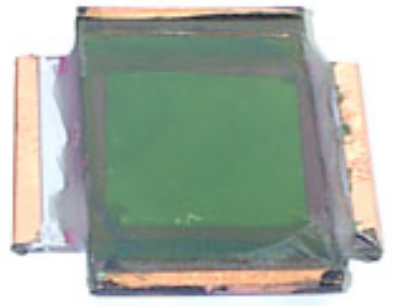

Reflective (Back)

Fig. 17 A REM smart window device with polyaniline counter electrode.

\subsection{Demonstration Device Fabrication}

Work on this task was directed toward fabrication of a large-area (30-cm square) demonstration device with a dot matrix counter electrode. Two large-area demonstration devices (30-cm square) were fabricated but could not be characterized or cycle tested since mirror formation was not observed due to defective platinum nucleation layers provided by an outside supplier. The platinum layers should not have been too thin since the thickness specified was 25 Angstroms whereas only 15 Angstroms is required. The nucleation layer problem was verified and shown to result from defective ITO by building smaller cells with the same ITO material platinized at RSC, which also did not form mirrors over most of the electrode area. A smaller demonstration device (10-cm square) was delivered to the DOE. 


\subsubsection{Automated Dot Counting}

The Image J computer program was evaluated for automated determination of the total cross-sectional dot area using high-contrast SEM micrographs of eight spots on each of three dot matrix electrodes (Gen-9 ITO). Hand counting (minimum of 600 dots per spot) yielded dot diameters of $3.4 \mu \mathrm{m}$ (electrode \#3), $3.3 \mu \mathrm{m}$ (electrode \#4) and $3.0 \mu \mathrm{m}$ (electrode \#5). The hand count and computer yielded practically the same percentage cross-sectional area: respectively, 12.4 and $12.7 \%$ (electrode \#3); 15.3 and 15.4\% (electrode \#4); and 12.9\% and $12.2 \%$ (electrode \#5). The hand count and the calculated computer count (computer area divided by dot area from the hand diameter) were also in close agreement: respectively, 1.28 and $1.31 \mathrm{million} / \mathrm{cm}^{2}$ (electrode \#3); 1.76 and $1.76 \mathrm{million} / \mathrm{cm}^{2}$ (electrode \#4); and 1.76 and 1.67 million $/ \mathrm{cm}^{2}$ (electrode \#5). The actual computer counts were higher but could be brought into close agreement with the hand count by correcting for clusters of contiguous dots (counted as one dot by the computer). These data show that the computer readily provides a reliable measure of the total dot cross-sectional area needed to control the current density at dot matrix electrodes.

\subsubsection{Plating of Large-Area Dot Matrix Electrode}

The alkaline plating bath used to deposit platinum nuclei on ITO for dot matrix electrodes does not utilize organic additives and should ultimately be easy to control. As the bath was used, however, the Pt dot density tended to increase (from 2 to $3-4 \mathrm{million} / \mathrm{cm}^{2}$ ) and exhibit more voltage dependence, compared to that for fresh baths. In the long-term, methods will be developed for controlling the plating bath so that consistent results are obtained. In the short-term, it was necessary to reduce the plating voltage slightly and design the plating cell so that voltage variations along the electrode were minimized. The volume of the cell was constrained by the high cost of the gold plating solution.

The initial approach was to use a nanoporous glass sheet (Corning Thirstyglas ${ }^{\circledR}$ ) to provide a high electrical resistance between the cathode and the anode. However, contaminants that leach from the nanoporous glass into the plating bath were found to adversely affect the adhesion of the Pt dots to the ITO surface.

Experiments were also performed to determine whether uniform plating of Pt dots over large areas could be attained by plating with an area-graded counter electrode, comprised of a plastic frame supporting parallel Pt wire segments of variable spacing. In this case, differences in the polarization of the wire segments (at which oxygen evolution occurs) would be used to compensate for the voltage drops associated with sheet resistance of the ITO substrate used for the dot matrix electrode. The anodic current density was measured as a function of potential (vs. SCE) for a Pt electrode in the plating bath at temperature $\left(80^{\circ} \mathrm{C}\right)$. Not surprisingly, the current-voltage relationship for the oxygen evolution reaction on $\mathrm{Pt}$ exhibited two regions, presumably associated with the role of the peroxide intermediate. Unfortunately, reproducible currents were only obtained for the higher potential region, for which the currents are too high to be useful for controlling the uniformity of dot plating via the counter electrode polarization. 
A sufficiently uniform dot distribution was attained by using a plastic wedge between the cathode and anode so that the solution resistance was increased toward the buss bars. The plating cell employed a seal directly to the dot matrix electrode so as to minimize the volume of plating solution and facilitate heating in a water bath. The electrode in this case also had a resistive innerlayer ( $3000 \AA$ of silicon dioxide sandwiched between a 10 -ohm ITO underlayer and a 100-ohm ITO overlayer) to reduce the effects of the electrode sheet resistance. Largearea electrodes with resistive innerlayers were procured from two suppliers. The optimum dot density $\left(1-2 \mathrm{million} / \mathrm{cm}^{2}\right)$ was attained, indicating that the silicon oxide innerlayer did not significantly affect the properties of the ITO overlayer. 